\title{
Scintillometry in urban and complex environments: a review
}

Article

Accepted Version

Ward, H. C. (2017) Scintillometry in urban and complex environments: a review. Measurement Science and Technology, 28 (6). 064005. ISSN 1361-6501 doi: https://doi.org/10.1088/1361-6501/aa5e85 Available at https://centaur.reading.ac.uk/70101/

It is advisable to refer to the publisher's version if you intend to cite from the work. See Guidance on citing.

To link to this article DOI: http://dx.doi.org/10.1088/1361-6501/aa5e85

Publisher: IOP Publishing

All outputs in CentAUR are protected by Intellectual Property Rights law, including copyright law. Copyright and IPR is retained by the creators or other copyright holders. Terms and conditions for use of this material are defined in the End User Agreement.

\section{www.reading.ac.uk/centaur}

\section{CentAUR}

Central Archive at the University of Reading

Reading's research outputs online 


\title{
Scintillometry in urban and complex environments: a review
}

\author{
Helen C. Ward \\ Department of Meteorology, University of Reading, Reading, UK RG6 6BB \\ Author email: $\underline{\text { h.c.ward@reading.ac.uk }}$
}

\section{Abstract}

Knowledge of turbulent exchange in complex environments is relevant to a wide range of hydrometeorological applications. Observations are required to improve understanding and inform model parameterisations but the very nature of complex environments presents challenges for measurements. Scintillometry offers several advantages as a technique for providing spatiallyintegrated turbulence data (structure parameters and fluxes), particularly in areas that would be impracticable to monitor using eddy covariance, such as across a valley, above a city or over heterogeneous landscapes. Despite much of scintillometry theory assuming flat, homogeneous surfaces and ideal conditions, over the last 20 years scintillometers have been deployed in increasingly complex locations, including urban and mountainous areas. This review draws together fundamental and applied research in complex environments, to assess what has been learnt, summarise the stateof-the-art and identify key areas for future research. Particular attention is given to evidence, or relative lack thereof, of the impact of complex environments on scintillometer data. Practical and theoretical considerations to account for the effects of complexity are discussed, with the aim of developing measurement capability towards more reliable and accurate observations in future. The usefulness of structure parameter measurements (in addition to fluxes, which must be derived using similarity theory) should not be overlooked, particularly when comparing or combining scintillometry with other measurement techniques and model simulations.

Keywords: heterogeneous landscape; scintillometer; similarity theory; structure parameter; surface flux; turbulence

\section{Introduction}

Much of the understanding underpinning current meteorological measurement and modelling capabilities is based on ideal environments, i.e. extensive areas of flat terrain with uniform surface characteristics (Rotach et al., 2004; Rotach et al., 2008). However, a vast proportion of the earth's land surface does not conform to these ideals. Heterogeneity in surface characteristics can result from natural variation (in soil characteristics, sun-shade conditions, altitude, vegetation) as well as through human influences (agriculture, urbanisation). In urban areas, contrasting land cover characteristics, distribution of energy sources and size, layout and material properties of buildings can lead to extreme heterogeneity in terms of aerodynamic and thermal properties (Schmid et al., 1991). In regions with uneven terrain, surface heterogeneity results from differential heating by solar radiation (Whiteman et al., 1989; Matzinger et al., 2003). Even over ideal surfaces spatial variability in weather can result in inhomogeneity, for example rainfall causing uneven wetting or patchy cloud cover causing uneven heating.

To make reliable predictions, observations are required to first understand the exchange of energy, moisture, momentum or pollutants between surface and atmosphere. These observations can then be used to inform and evaluate model parameterisations. Accurate interpretation of field data in complex environments requires understanding of relevant physical processes, how they differ from the ideal case and their potential impact on observations. 
The most widely accepted technique for measuring surface fluxes is eddy covariance (EC) (Baldocchi et al., 2001). Fast measurements of the wind components, sonic temperature and gas concentrations (typically water vapour and carbon dioxide) are made by a sonic anemometer and gas analyser installed on a tower several metres above the surface. EC data are typically representative of a single field or neighbourhood (i.e. $10^{2}-10^{3} \mathrm{~m}$ ).

Scintillometers provide measurements at a much larger scale. Scintillometry is a ground-based remote-sensing technique that uses changes in the refractive index of air to derive turbulence statistics. An electromagnetic beam propagates through the atmosphere from transmitter to receiver (Figure 1). Turbulent eddies moving in and out of the beam scatter the radiation. The amount of scattering depends on the refractive index $(n)$ of air parcels, which depends on their density $(\rho)$ which, in turn, depends on their temperature $(T)$ and water vapour content (specific humidity, $q$ ). From the fluctuations in $T$ and $q$, surface fluxes can be obtained using Monin-Obukhov similarity theory (MOST). As the received intensity is the result of fluctuations all along the beam, derived quantities are spatially-integrated.

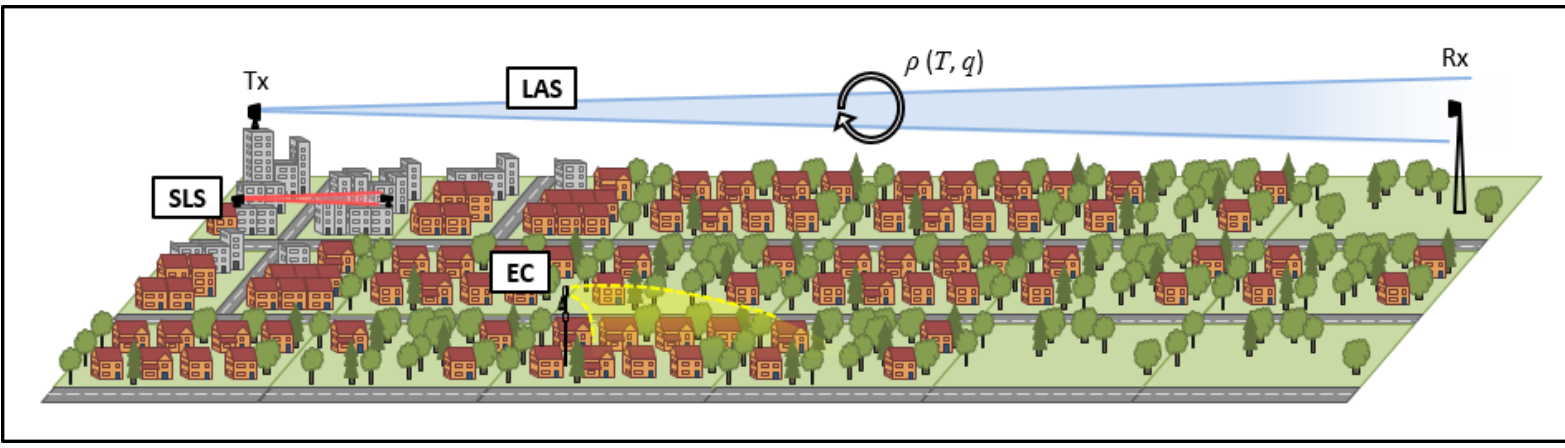

Figure 1: Schematic representation (not to scale) of a large-aperture scintillometer (LAS, blue), surface-layer scintillometer (SLS, red) and eddy covariance station (EC, yellow) deployed over a complex landscape. As the scintillometer beam propagates from transmitter (Tx) to receiver (Rx) it is scattered by turbulent eddies of density $\rho$ at temperature $T$ and humidity $q$.

Scintillometers vary principally in terms of wavelength $(\lambda)$ of the electromagnetic beam and size of the aperture. In the infrared region, refractive index fluctuations are mainly caused by changes in air temperature with humidity having a much smaller effect. Therefore infrared scintillometers are used to find the sensible heat flux. Large-aperture scintillometers (LAS) are relatively insensitive to eddies smaller than their aperture diameter $(D \approx 0.15 \mathrm{~m})$ so can be used over long distances (Wang et al., 1978), usually between 500 and $5000 \mathrm{~m}$. For longer paths (up to $10000 \mathrm{~m}$ ) extra-large aperture scintillometers (XLAS) are recommended. Small-aperture (near-)infrared scintillometers are affected by eddies of similar size to the inner-scale, $l_{0}$ (Section 2.1). Two beams are therefore required to derive both the refractive index fluctuations and $l_{0}$. These are known as displaced-beam small-aperture scintillometers, or surface-layer scintillometers (SLS) and operate across paths of $50-250 \mathrm{~m}$. Scintillometers of longer wavelengths (millimetre-wave, microwave or radio-wave) are sensitive to fluctuations in both air temperature and humidity, so these instruments (denoted MWS) can be used in conjunction with an infrared LAS to determine sensible and latent heat fluxes. A value for the temperature-humidity correlation coefficient $\left(r_{T q}\right)$ must either be assumed ('two-wavelength' method (Hill et al., 1988; Andreas, 1989)) or obtained from the covariance between the two signal intensities ('bichromatic correlation' method (Lüdi et al., 2005)). Figure 2 summarises the various methods of obtaining fluxes from scintillometry. 


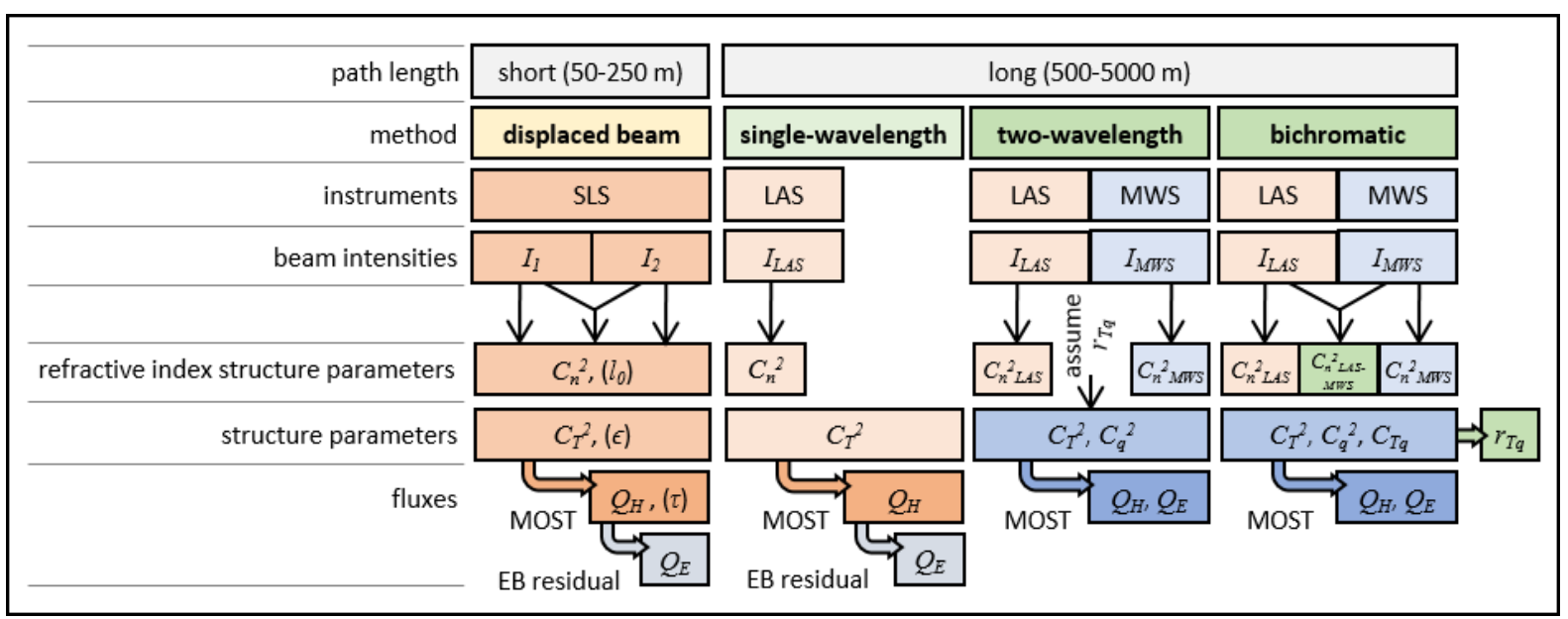

Figure 2: Summary of methods to obtain turbulent heat fluxes (and momentum flux, $\tau$ ) from scintillometers via MoninObukhov similarity theory (MOST) or energy balance (EB) residual. $I$ is beam intensity. Other notation is defined in the text.

This review focuses on scintillometry in complex environments, where 'complex' describes some departure from the ideal (flat, homogeneous) case and therefore includes urban areas and variable topography. Published reviews of scintillometry are rare and much needed. Hill (1992) provides a comprehensive summary of optical scintillation before the application to complex environments really began, and a useful overview of surface-layer scintillometry is Odhiambo and Savage (2009). Here, the focus is on turbulence (i.e. structure parameters and fluxes). Given the volume and variety of studies in the last 20 years (Figure 3), combined with advances in the tools available (instrumentation, data loggers, numerical modelling, earth observation), this review is timely and relevant. Particular attention is given to potential issues with the application of scintillometry in complex environments and efforts that have been made to address these issues. The importance of this is to encourage best practice in future for the growing number of research groups using scintillometry.

This article is structured as follows. Basic theory is outlined in Section 2. Key findings from studies in increasingly challenging environments are analysed in Section 3, with an emphasis on fundamental progress in understanding scintillometry and boundary-layer processes. Theoretical and practical considerations relating to complex environments are examined in Section 4. A summary and outlook is given in Section 5 .

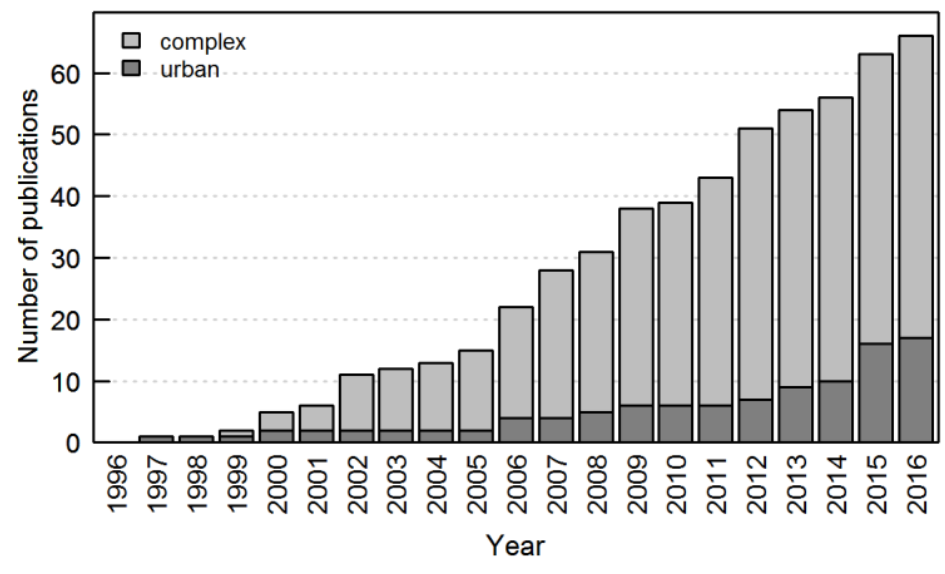

Figure 3: Cumulative number of journal articles reporting scintillometry observations in complex and urban environments over the last 20 years. Only articles dealing with structure parameters and fluxes were counted. See Table 2 for references and further details. 


\section{Theory}

\subsection{Relating intensity fluctuations to the strength of turbulence}

Turbulent transport is the primary mechanism by which heat, moisture and other scalars are redistributed within the near-surface boundary layer. Large-scale eddies (of the order of half the height of the boundary layer) generated by wind shear and convection break down into smaller and smaller eddies until their energy is dissipated as heat by molecular viscosity. This cascade process results in a turbulence spectrum of three parts: the production range consisting of the largest eddies; the inertial subrange containing eddies from tens of metres (or half the measurement height) to millimetres (the inner scale); and the dissipation range (e.g., Meijninger, 2003; Hartogensis, 2006; Moene et al., 2009). Within the inertial subrange, production and dissipation processes are unimportant and homogeneous and isotropic turbulence can be described by the three-dimensional Kolmogorov spectrum (Monin and Yaglom, 1971):

$$
\Phi_{n}(K)=0.033 C_{n}^{2} K^{-11 / 3}
$$

where $K$ is the eddy wavenumber (defined as $K=2 \pi / l$ where $l$ is eddy size) and $C_{n}{ }^{2}$ is the structure parameter of the refractive index of air. For SLSs the spectrum should be modified to more accurately represent behaviour at small scales (e.g., Hill, 1988; Frehlich, 1992). $C_{n}^{2}$ can be related to intensity fluctuations, expressed in terms of the variance of log-amplitude fluctuations $\sigma_{\chi}^{2}$, using the following equation (in generalised form) (Lüdi et al., 2005):

$$
\begin{aligned}
\sigma_{\chi 1 \chi^{2}}= & 4 \pi^{2} k_{1} k_{2} 0.033 C_{n}^{2} \int_{0}^{\infty} d K \int_{0}^{L} d x K^{-8 / 3} \sin \left(\frac{K^{2} x(L-x)}{2 k_{1} L}\right) \sin \left(\frac{K^{2} x(L-x)}{2 k_{2} L}\right) \\
& \times\left[\frac{2 J_{1}\left(0.5 K D_{r 1} x / L\right)}{0.5 K D_{r 1} x / L}\right]\left[\frac{2 J_{1}\left(0.5 K D_{t 1}(1-x / L)\right)}{0.5 K D_{t 1}(1-x / L)}\right] \\
& \times\left[\frac{2 J_{1}\left(0.5 K D_{r 2} x / L\right)}{0.5 K D_{r 2} x / L}\right]\left[\frac{2 J_{1}\left(0.5 K D_{t 2}(1-x / L)\right)}{0.5 K D_{t 2}(1-x / L)}\right] J_{0}(K|d|)
\end{aligned}
$$

where $k$ is the optical wavenumber $(k=2 \pi / \lambda), x$ the normalised position along the path, $L$ the path length, $d$ the displacement between beams, $J_{0}$ and $J_{l}$ are Bessel functions, $t$ denotes transmitter, $r$ receiver and the subscripts 1 and 2 refer to each beam. For a single instrument the subscripted quantities are the same and integration yields an equation relating the variance of log-amplitude fluctuations to the strength of turbulence, described by the path-averaged structure parameter of the refractive index of air. For example, for a LAS (Wang et al., 1978),

$$
\sigma_{\chi}^{2}=0.223 D^{-7 / 3} L^{3} C_{n}^{2}
$$

The derivation assumes weak scattering, homogeneous turbulence and that $C_{n}{ }^{2}$ only varies smoothly along the path so that local isotropy applies (Moene et al., 2004). Integrating Eq 2 over $K$ gives the path weighting function, which describes the sensitivity of the scintillometer as a function of position along the path. The sensitivity is greatest for the middle third of the path and very small towards the ends of the path.

\subsection{Relating refractive index fluctuations to temperature and humidity fluctuations} $C_{n}{ }^{2}$ can be split into contributions from temperature and humidity fluctuations (Hill et al., 1980), 


$$
C_{n}^{2}=\frac{A_{T}^{2}}{T^{2}} C_{T}^{2}+2 \frac{A_{T} A_{q}}{T q} C_{T q}+\frac{A_{q}^{2}}{q^{2}} C_{q}^{2}
$$

where $C_{T}^{2}$ is the structure parameter of temperature, $C_{q}^{2}$ is the structure parameter of specific humidity and $C_{T q}$ is the temperature-humidity cross structure parameter. The coefficients $A_{T}$ and $A_{q}$ depend on wavelength and are given in Ward et al. (2013). Solving this equation depends on the instrumental setup (Figure 2). For a two-wavelength system, Eq 4 can be written for each wavelength, allowing both $C_{T}^{2}$ and $C_{q}^{2}$ to be found if a value of the temperature-humidity correlation coefficient $r_{T q}$ is assumed so that the cross term can be eliminated (Hill et al., 1988; Andreas, 1989). The bichromatic method uses the correlation between each scintillometer beam to provide a third equation of similar form to Eq 4, which enables $C_{T}{ }^{2}, C_{q}{ }^{2}$ and $C_{T q}$ (and thus $r_{T q}$ ) to be found directly (Lüdi et al., 2005; Ward et al., 2015b). For the typical single-wavelength setup, the first term on the RHS of Eq 4 usually dominates so the $C_{T q}$ and $C_{q}{ }^{2}$ contributions can be approximated using the Bowen ratio $\beta$ (= $Q_{H} / Q_{E}$, the ratio of sensible to latent heat flux) (Wesely, 1976; Moene, 2003),

$$
C_{n}^{2} \approx \frac{A_{T}^{2}}{T^{2}} C_{T}^{2}\left(1+\frac{0.03}{\beta}\right)^{2}
$$

Strictly, the appearance of $\beta$ here is based on the assumption $\left|r_{T q}\right|=1$ and the value 0.03 is for standard atmospheric conditions (pressure, $p=10^{5} \mathrm{~Pa}, T=300 \mathrm{~K}$ ). Applying the $\beta$ approximation (instead of the full formula involving the standard deviations of $T$ and $q$, see Moene (2003) Eq 8) can lead to errors in $C_{T}^{2}$ of $5-40 \%$ for $|\beta|<1$. The absolute impact on the energy budget is small, however, as the correction is negligible when $Q_{H}$ is large and when the correction is substantial $Q_{H}$ is small.

\subsection{Relating structure parameters to fluxes}

The conversion of structure parameters to fluxes relies on MOST, which requires homogeneous and stationary conditions. Wind speed, $U$, is used to estimate the friction velocity, $u_{*}$, assuming a logarithmic wind profile adjusted for stability (e.g., Stull, 1988). The Okukhov length, $L_{O b}$, and the temperature scaling variable, $T *$, are calculated iteratively using the following equations:

$$
\begin{aligned}
& u_{*}=\frac{\kappa_{v} U}{\ln \left(\frac{z_{u}-z_{d}}{z_{0}}\right)-\Psi_{m}\left(\frac{z_{u}-z_{d}}{L_{O b}}\right)}, \\
& \frac{C_{T}^{2}\left(z_{m}-z_{d}\right)^{2 / 3}}{T_{*}^{2}}=f_{M O}\left(\frac{z_{m}-z_{d}}{L_{O b}}\right), \\
& L_{O b}=\frac{u_{*}^{2} T}{g \kappa_{v} T_{*}\left(1+\frac{0.07}{\beta}\right)}
\end{aligned}
$$

where $\kappa_{v}$ is the von Kármán constant, $z_{u}$ the height of the wind speed measurement, $z_{m}$ the height of the scintillometer beam, $z_{d}$ zero-plane displacement height, $z_{0}$ roughness length for momentum, $g$ acceleration due to gravity, $\Psi_{m}$ the integrated stability function for momentum (e.g., Panofsky and Dutton, 1984) and $f_{M O}$ is a similarity function (Section 4.1.1). Scintillometry does not provide the sign of the sensible heat flux, so additional information is required to determine whether stable or unstable similarity functions should be used (Samain et al., 2012a). For SLSs, measured $U$ is not required as $u$ * 
is instead obtained from the turbulent kinetic energy dissipation rate, $\epsilon$, via MOST (Wyngaard and Clifford, 1978; Thiermann and Grassl, 1992).

The sensible heat flux is calculated,

$$
Q_{H}=-\rho c_{p} u_{*} T_{*}
$$

where $\rho$ is the density of air and $c_{p}$ the specific heat capacity of air at constant pressure. For twowavelength systems the humidity scaling variable, $q_{*}$, is obtained analogously from $C_{q}{ }^{2}$, then the latent heat flux is obtained from,

$$
Q_{E}=-\rho L_{v} u_{*} q_{*}
$$

where $L_{v}$ is the latent heat of vaporisation. For a standalone infrared scintillometer $Q_{E}$ is instead obtained from the residual of the energy balance (Section 4.4).

\section{Progress in scintillometry}

This section is devoted to studies investigating fundamental science questions and advancing understanding of boundary-layer meteorology or scintillometry itself. For a more exhaustive overview of scintillometry studies in complex environments, Table 2 (Appendix) summarises instrumentation, site details and key findings.

The performance of scintillometry is often judged by its ability to match EC. However, uncertainties with EC and differences between the techniques must be considered. Although EC is a direct method of measuring fluxes, data processing consists of a series of adjustments and corrections (Aubinet et al., 2012) and different options can lead to differences of 10-15\% in the fluxes (Mauder et al., 2007). As with scintillometry, EC measurements were also developed for flat homogeneous sites and application at more complex sites potentially introduces uncertainties and may require different treatment (Finnigan, 2008; Stiperski and Rotach, 2016). The main issue with EC is under-closure of the energy balance: the sum of the turbulent heat fluxes is often smaller than the available energy by 10$30 \%$ (Wilson et al., 2002; Foken, 2008). Despite research into the source of this energy imbalance, the full explanation remains elusive. Suggestions include sampling errors related to inconsistent source areas for the energy balance terms; advection or storage terms not accounted for; instrument bias; and missing low or high frequency contributions. Some studies force closure by increasing $Q_{H}$ and $Q_{E}$ while maintaining $\beta$ (Twine et al., 2000). In the following, the subscripts 'sc', 'EC' and 'agg' are used to denote scintillometry, eddy covariance and area-aggregated datasets.

More recently, other options for assessing scintillometer performance have emerged, including airborne measurements, numerical modelling (mesoscale weather models and large eddy simulation, LES) and satellite products. These enable analysis to extend beyond the limitations of the now familiar EC-scintillometry comparison and provide a broader understanding (being limited by a different set of issues to $\mathrm{EC})$.

\subsection{Heterogeneous environments}

By the end of the 1990s, scintillometry had been shown to be a useful technique for deriving surface fluxes over flat homogeneous landscapes (e.g., Hill et al., 1992; De Bruin et al., 1995; McAneney et al., 1995) and interest grew in the applicability of scintillometry to heterogeneous surfaces (De Bruin, 2002). Initial studies considered the simplest case: two-surface composite paths where the scintillometer provides spatially-integrated measurements over both surfaces. Chehbouni et al. (2000) found 'fairly good' agreement between $Q_{H}$ from a LAS spanning two patches ( $45 \%$ grass, 
$55 \%$ mesquite) and $Q_{H}$ from EC stations in each patch aggregated according to the scintillometer path weighting function. A very similar study ( $25 \%$ grass, $75 \%$ mixed mesquite and grass) found 'very good' agreement between $Q_{H_{-} s c}$ and $Q_{H_{-} E C_{-} a g g}\left(r^{2}=0.95\right)$ (Chehbouni et al., 1999). For both of these short studies, agreement between LAS and EC for the composite path was similar to or better than comparisons for each patch individually. It was suggested that the methodology could be improved with a dynamic aggregation scheme that would account for the changing composition of the LAS measurement (i.e. a scintillometer footprint model).

Lagouarde et al. (2002) also used a composite path, over wheat and bare soil, introducing a step change in crop height as well as vegetation type. Good correlation $\left(r^{2}=0.96\right)$ was found, but $Q_{H_{-} s c}$ overestimated $Q_{H_{-} E C_{-} a g g}$ by $11 \%$. This was largely explained by a fundamental difference between scintillometry and EC techniques: rather than measuring fluxes directly, scintillometers measure pathaveraged structure parameters which are non-linearly related to $Q_{H}$. For a heterogeneous surface, averaging $C_{T}^{2}$ and then converting to $Q_{H}$ will give different results to averaging $Q_{H}$ from each of the individual patches. This property is clearly illustrated by Meijninger et al. (2006) (see their Figure 10) where it is also extended to include $Q_{E}$ derived via $C_{q}{ }^{2}$. When used below the blending height (see Section 4.1), scintillometry is expected to overestimate aggregated fluxes in heterogeneous landscapes by a few percent, depending mainly on the difference in fluxes between patches. Increasing the measurement height reduces the overestimation for $Q_{H}$, but was found to increase the overestimation for $Q_{E}$ (Meijninger et al., 2006). Lagouarde et al. (2002) proposed a correction based on a rough estimate of the difference in $Q_{H}$ between patches, but it has rarely been implemented.

Assessing scintillometer performance in heterogeneous environments was revolutionised by the introduction of a scintillometer footprint function. Point source area models used for EC (Leclerc and Foken, 2014) are computed at several locations along the path and combined with the path weighting function, resulting in a source area along and (usually) upwind of the path, with greatest weight near the centre of the path. Meijninger et al. (2002b) introduced this approach in order to dynamically aggregate EC fluxes measured over multiple crop types in the Flevoland field campaign to match the changing composition of the scintillometer source area. The dynamic aggregation resulted in a 1:1 agreement between $Q_{H_{-} s c}$ and $Q_{H_{-} E C_{-} a g g}$ and this approach is now used routinely for comparisons between datasets.

At the Flevoland site, typical field sizes were $200-500 \mathrm{~m}$ (depending on wind direction) and the path length was $2200 \mathrm{~m}$. The LITFASS campaigns address heterogeneity at a much larger scale (Beyrich et al., 2002b; 2006; 2012). The LITFASS region includes agricultural fields, grasslands, forests and lakes and also incorporates moderate topography. The main scintillometer path length (now operational for $>10$ years) is $4700 \mathrm{~m}$. Using EC, short- and long-path scintillometers, airborne instrumentation and modelling, the LITFASS campaigns have substantially advanced understanding of turbulent exchange over heterogeneous surfaces. During LITFASS-2003 fourteen EC stations were operated over different crops and surface types (Beyrich and Mengelkamp, 2006). 'Encouraging' agreement was obtained between aggregated EC fluxes and fluxes derived from a two-wavelength scintillometer system $\left(r^{2}=\right.$ 0.8-0.9) (Meijninger et al., 2006). Scintillometer fluxes were higher than aggregated EC fluxes, attributed to under-closure of the energy balance and the non-linear relationship between structure parameters and fluxes. Other reasons for differences between methods include saturation of the LAS and uncertainty in similarity functions. An XLAS (path length $10.2 \mathrm{~km}$ ) over the same region required a substantial saturation correction to achieve reasonable agreement with $Q_{H_{-} E C_{-} a g g}$ (Kohsiek et al., 2006).

Numerous other studies comparing EC and scintillometry report similar findings (Table 2). In Ghana $Q_{H}$ and $Q_{E}$ derived from LASs and the energy balance residual were compared with EC data for two 
heterogeneous savannah sites (Schüttemeyer et al., 2006). Agreement in $Q_{H}$ was poorer at the more heterogeneous 'Ejura' site $\left(r^{2} \approx 0.7\right.$ compared to $\left.\approx 0.9\right)$, possibly due to the small size of the EC source area and a larger scale of heterogeneity, although this is not demonstrated conclusively. In a similar study, good agreement between LAS and EC was found for a mixed vegetation site in Benin (Guyot et al., 2009). Again, scatter was linked to mismatches in the LAS and EC footprint, but both techniques captured changes in the surface energy balance after rainfall. Remarkable agreement was found between $Q_{H_{-} s c}$ and $Q_{H_{-} E C_{-} a g g}$ over mixed agricultural landscape with undulating terrain (Evans et al., 2012), even as crops matured and energy partitioning within the fields changed. Correlation between $Q_{H_{-} s c}$ and $Q_{H_{-} E C_{-} a g g}$ was higher $\left(r^{2}=0.94\right)$ than between $Q_{H_{-} s c}$ and $Q_{H_{-} E C}$ for each of the individual fields $\left(r^{2}=0.75-0.91\right)$ and the regression slope obtained for the aggregated flux was 1.00 , while slopes for individual fields varied from 0.68 to 2.06. $Q_{E_{-} s c}$ calculated as the energy balance residual using aggregated net radiation and soil heat flux also agreed well with $Q_{E_{-} E C_{-} a g g}\left(r^{2}=0.75\right.$, slope $\left.=0.94\right)$. Ezzahar et al. (2009b) compared $Q_{H_{-} s c}$ with $Q_{H_{-} E C_{-} a g g}$ from three land cover types (shrubs, fallow, crops) in Niger and found good agreement in $Q_{H}\left(r^{2}=0.85\right)$ and $Q_{E}$ estimated from the energy balance $\left(r^{2}=0.75\right)$. Ezzahar et al. (2007a) investigated heterogeneity due to differences in soil moisture across an olive yard in Morocco. They installed LAS and EC systems in adjacent irrigated and unirrigated fields but, as it was not feasible to install a third LAS across both fields, an aggregation scheme was used to calculate area-averaged $C_{n}^{2}$. It was concluded that area-averaged $C_{T}^{2}$ generally behaves according to MOST. Hoedjes et al. (2007) use thermal imagery and footprint modelling to neatly explain observed differences between EC and LAS fluxes from one of the olive yards as the surface changes from almost homogenous (before and after irrigation) to highly heterogeneous (during irrigation). During irrigation, clear differences were observed between $Q_{H_{-} E C}$ and $Q_{H_{-} s c}\left(r^{2}=0.80\right.$, regression offset $=$ $\left.49.88 \mathrm{~W} \mathrm{~m}^{-2}\right)$, compared to before/after $\left(r^{2}=0.93-5\right.$, offset $\left.=28.42 / 11.25 \mathrm{~W} \mathrm{~m}^{-2}\right)$. Footprint-weighted radiative surface temperatures were calculated for EC and LAS using ASTER and Landsat data, and found to correlate with differences in $Q_{H}$ when the difference between the two exceeds $0.5^{\circ} \mathrm{C}$ (smaller differences in radiative surface temperature indicate a more similar footprint composition and differences in $Q_{H}$ at these times are believed to be for other reasons). A similar approach was used to assess heterogeneity within and between LAS and EC footprints at an alpine meadow site in China, which partially explained differences in the observed fluxes (Liu et al., 2011).

Hence these studies (and others, Table 2) demonstrate scintillometry can be used to give reasonable fluxes in heterogeneous environments. Validation against aggregated EC datasets frequently demonstrates somewhere between reasonable and excellent agreement, at least under unstable conditions. Differences are usually attributable to uncertainties in one or other (or both) datasets (energy balance closure, footprint differences, saturation, similarity functions and instrument uncertainties being the main ones), which can somewhat unsatisfactorily limit further insight.

To attempt to eliminate some of these issues, analysis of structure parameters can help separate out differences in techniques from uncertainties involved in the flux calculation. As scintillometers essentially measure structure parameters, deeper understanding of their behaviour is extremely relevant. Using EC data, Braam et al. (2014b) investigated structure parameter measurements over heterogeneous surfaces in an attempt to distinguish local variability due to the nature of the turbulent field from spatial variabilty related to surface characteristics. During LITFASS-2009 an automated unmanned aircraft flown along the scintillometer path revealed spatial variability in $C_{T}^{2}$, however it was not possible to determine from a single flight whether this variability was related to surface heterogeneity since the pattern was observed to change on the timescale of a few minutes (Braam et al., 2016). Careful consideration of data processing decisions and errors in LAS and aircraft measurements (Braam et al., 2016) represents important progress in these fairly novel techniques, 
however, analyses indicate $C_{T}^{2}$ from the aircraft is significantly higher than from scintillometer or EC data, calling for further measurement campaigns.

Earlier studies comparing airborne and ground-based fluxes took a broader approach. Good agreement was obtained during LITFASS-1998 (Bange et al., 2002): $Q_{H}$ at $80 \mathrm{~m}$ height, derived from a turbulence probe mounted beneath a helicopter (Helipod), correlated well with the variations in land cover below, being higher over forest and lower over water. The results for $Q_{E}$ were less clear, but it was suggested that, over water, turbulence was decoupled from the surface on account of the lower roughness. For LITFASS-2003, Helipod, scintillometer and aggregated EC fluxes exhibited consistent diurnal cycles on the example day presented in Beyrich et al. (2006). The recent analyses focusing on structure parameters allow for a more critical diagnosis; it is possible for derived fluxes to show good agreement if there are compensating errors in the inputs (e.g., De Bruin et al., 2002) or relatively poor agreement but within sizeable uncertainty estimates.

Another approach to deciphering scintillometer measurements is high resolution modelling. Maronga et al. $(2013 ; 2014)$ used LES to investigate $C_{T}{ }^{2}$ and $C_{q}{ }^{2}$ for the surface layer above the LITFASS region. A cross-section of the simulated boundary layer at the height of the LAS path revealed clear signatures in $C_{T}^{2}$ and $C_{q}{ }^{2}$ that correlated with patches of forest (large $Q_{H}$ ) and oil-seed rape (large $Q_{E}$ ). By sampling the LES data according to the scintillometer path weighting, direct comparison between path-averaged structure parameters measured by the LAS and modelled by the 'virtual LAS' is possible. These studies demonstrate that LES is a very powerful tool that can be used, and surely will be used increasingly, to help understand measurements.

Beyrich et al. (2002a) compared sensible heat fluxes from the long-term LAS path at the LITFASS site with output from a numerical weather prediction model. A comparison of monthly diurnal cycles reveals reasonably good agreement (differences between model and observations are generally smaller than the variation within each month), but since the model has been tuned to accurately predict two-metre air temperature by reducing $Q_{E}$, it overestimates $Q_{H}$ compared to the LAS during summer, particularly during wet conditions when the impact of the tuning is largest. In winter, $Q_{H_{-} s c}$ overestimated modelled values, possibly due to reduced applicability of similarity functions.

Samain et al. (2011) deployed an XLAS on a path of $9.5 \mathrm{~km}$ to obtain $Q_{H}$ over a heterogeneous catchment including agriculture, pasture, forests and urban areas in Belgium. Results were assessed using a calibrated and validated energy and water balance model (TOPLATS) in conjunction with the XLAS footprint, and $Q_{H_{-} s c}$ was judged to be representative of the entire catchment $\left(\sim 100 \mathrm{~km}^{2}\right)$. Explanations given for differences between modelled and observed $Q_{H}$ for the scintillometer source area include saturation, non-applicability of similarity functions and flux divergence on account of the height of the beam (effective height $z_{e f}=68 \mathrm{~m}$ ). Using area-average estimates of net all-wave radiation, $Q^{*}$, and ground heat flux, $Q_{G}$, catchment-scale $Q_{E}$ was estimated as the residual of the energy balance and compared with ETLook, a surface energy balance algorithm based on remote sensing data (Samain et al., 2012b). The study concludes that an XLAS paired with representative available energy measurements is better suited than ETLook for providing hourly evaporation estimates needed for flood forecasting.

The measurement scale of long-path scintillometers is well suited for comparison with remote sensing products, but due to the large uncertainties in satellite-based estimates of surface fluxes, comparisons between scintillometer and remote-sensing products are typically used as a method of validating the latter (Schüttemeyer et al., 2007; Marx et al., 2008; Kleissl et al., 2009; Brunsell et al., 2011; Jia et al., 2012). In many of these studies, large-area evaporation is the quantity of interest for agricultural or hydrological applications. The errors that can be introduced via poor spatial estimates 
of net radiation and ground heat flux make a strong case for development and testing of twowavelength scintillometry.

\subsection{Complex topography}

Few scintillometry studies have been conducted in very steep terrain. Weiss (2002) describes a series of experiments under increasingly challenging conditions: homogenous and flat terrain, heterogeneous and flat terrain, and heterogeneous terrain in an alpine valley as part of the Riviera Project (Rotach et al., 2004). Although of short duration, comparison with EC data gives confidence in the performance of SLSS and it is concluded that scintillometers can be used to detect site-to-site differences in irregular terrain, such as the timing of peak $Q_{H}$ between slope and valley floor sites (Rotach et al., 2008). Hill et al. (1992) also found that SLSs can be used under non-ideal conditions where MOST would not be expected to hold (limited fetch and spatio-temporal variation due to cloud cover). The fact that SLSs are sensitive to small-scale eddies in the inertial dissipation range may explain why non-homogenous conditions appear not to have a detrimental impact on the technique: small-scale eddies adapt more rapidly to changing surface conditions and thus quickly regain equilibrium with the local terrain (Rotach and Zardi, 2007). Rather than complex terrain, limited applicability of MOST in neutral conditions and lack of consensus about the similarity functions were found to represent the biggest limitations.

As part of the i-Box network in the Alps, a LAS was installed across the valley with the centre of the path above an EC tower with three measurement levels: 4, 9, and $17 \mathrm{~m}$. On one of the example days discussed in Rotach et al. (2016), there is good agreement between the EC stations and LAS. In the afternoon of the second example day, $Q_{H}$ decreases with height so the LAS (at about $60 \mathrm{~m}$ ) reads much lower than the EC stations, but the decrease is observed for the EC data as well, implying that the height of the surface layer is somewhere below the top of the EC tower. As these experiments were of short duration, conducting similar studies over longer periods would be beneficial. Further insight is expected following analysis of aircraft data. Other scintillometry studies in mountainous regions have focused on wind speeds rather than fluxes (Table 2).

\subsection{Urban environments}

One of the first uses of scintillometry in urban areas was in Tokyo (Kanda et al., 2002), where two SLSs were used to derive $Q_{H}$ and $z_{d}$. Micro-scale studies using SLSs have also been carried out in Basel (Rotach et al., 2005), Lausanne (Nadeau et al., 2009) London (Pauscher, 2010) and Oklahoma (Galvez, 2011), and at the COSMO field site in Japan (Sugawara et al., 2016). With the exception of the higher paths in Tokyo and COSMO, these measurements are located within the roughness sublayer and are therefore influenced by the immediate surroundings.

Application of large-aperture scintillometry to the urban environment was first carried out in the relatively homogeneous centre of Marseille (Lagouarde et al., 2006). The homogeneity of the site and substantial height of the beams minimised many potential complexities. Standard non-urban forms of the similarity functions (Andreas (1988), hereafter An88, and De Bruin et al. (1993), hereafter DB93) were used. Good agreement was obtained with EC and with a second scintillometer path nearby, confirming the homogeneous nature of the site. $Q_{H_{-} s c}$ exhibited a smoother diurnal cycle than $Q_{H_{-} E C}$ as a result of the greater spatial averaging. Other urban locations where $Q_{H}$ has been derived from LASs include Nantes (Mestayer et al., 2011), Łódź (Zieliński et al., 2013), Helsinki (Wood et al., 2013a), Swindon (Ward et al., 2014) and London (Crawford et al., 2017). These are mostly multi-seasonal studies, describing the climatology of the sites rather than critically evaluating the performance of the technique. 
Recently, LASs have been deployed in Asian cities, for example at a highly heterogeneous site in Gongju, Korea (Lee et al., 2015) and on two short paths $(<500 \mathrm{~m}$ ) at suburban and urban sites in China (Zhang and Zhang, 2015). In the latter study, $Q_{H_{-} s c}$ was often much larger than $Q_{H_{-} E C}$. Wavelet analysis was used to investigate the distribution of length scales contributing to $Q_{H}$ (Zhang et al., 2016). Results suggested large-scale motions were important at the suburban site, but not at the urban site, which could explain the observed pattern of differences between LAS and EC datasets. To test the generality of these findings, similar analyses for other sites would be informative, for example to distinguish influences of surface characteristics from potential influences of the instrumental setup (here $z_{e f}=$ $30.0 \mathrm{~m}$ and $6.7 \mathrm{~m}$ at the urban and suburban sites, respectively).

LAS paths in urban areas are usually selected so that they are above the roughness sublayer, thereby permitting use of standard similarity theory to calculate fluxes and sidestepping issues related to surface heterogeneity. For long paths traversing land use zones, such as from the city centre to suburbs (e.g., Wood et al., 2013a), conditions probably vary smoothly enough that MOST is not seriously violated. Much of the extreme variability within urban environments occurs instead at the microscale (e.g., sunlit versus shaded walls) or plot-scale (e.g., a mixture of road, building and vegetated surfaces). Compared to LAS footprints this scale of heterogeneity is very small. However, there are clearly some situations where larger-scale heterogeneity persists. A river or park surrounded by dry built areas would be expected to generate extreme changes in surface energy partitioning which may present a greater measurement challenge (not restricted to scintillometry). Turbulence may not be well-mixed at the height of the measurements if internal boundary layers from contrasting surfaces persist (Kotthaus and Grimmond, 2014). Additionally, since scintillometers cannot determine the sign of the heat flux, the impact of simultaneous positive and negative $Q_{H}$ along the path is unknown (Chehbouni et al., 2000). Investigating the accuracy of the technique is very difficult in such complex urban environments. Lee et al. (2015) used high resolution numerical modelling to assess LAS performance over an urban river. The Weather Research and Forecasting (WRF) model was run for two days providing $Q_{H}$ at $200 \mathrm{~m}$ resolution, which was then averaged over the $2.1 \mathrm{~km}$ path. Observed and modelled values were fairly similar but $Q_{H_{-} s c}$ peaked earlier during the clear-sky day and hour-tohour variations were slightly different. The advantage of model comparisons is that sensitivity analyses can be conducted easily. When the river was replaced with vegetation in this study, the model underestimated $Q_{H}$ during the morning hours. With continued advances in computing power, it is becoming possible to run longer simulations to investigate a wider range of conditions. However, most models still require substantial validation themselves, especially in complex environments, so a careful approach is required to learn from both techniques. In this respect, well-designed experiments in more carefully controlled surroundings (e.g., scintillometers at several heights crossing a river surrounded by homogenous low vegetation) would be of substantial benefit in addressing some of these research questions.

Salmond et al. (2012) present results from the intensive observation period of the BUBBLE campaign in Basel in 2002, demonstrating that with careful experimental design and extremely detailed analysis, scintillometers can be used to gain insight into turbulence exchange in cities. Two SLSs were installed over a roof surface and over a street canyon. $Q_{H}$ from the roof surface was greater during the day and smaller at night, attributed partly to the low heat capacity of the roof materials compared to the canyon with its much greater surface area and ability to store and release heat. Differences in the observed fluxes with wind direction were related to the flow over the roof surface: before encountering the scintillometer beam southeasterly flows first pass over heated roof surfaces whereas northwesterly flows first pass over much cooler shaded roofs. In contrast, the canyon scintillometer data showed little difference between northwesterly and southeasterly flows. 


\section{Issues associated with scintillometry in complex environments}

Despite the theoretical basis of the technique, observational evidence suggests scintillometry can be used successfully in complex environments (Section 3), and actually offers many advantages. Large scintillometer footprints are generally less susceptible to variation in source area characteristics than point measurements, which also permits shorter averaging times ( minutes, see Hartogensis et al. (2002)). The path-weighting function reduces sensitivity towards the ends of the path so topography or buildings can be used as mounting structures without having a detrimental impact on the measurements, facilitating sampling of difficult regions (e.g., above a city or within a valley). Once installed, scintillometers require little maintenance. However, there are practical and theoretical aspects that should be considered to obtain reliable and accurate results in urban and complex environments.

\subsection{Applicability of MOST}

Monin-Obukhov similarity functions are widely used to calculate surface fluxes from profiles, variances or structure parameters of scalars. In the absence of an alternative framework, MOST is routinely applied to more complex situations than for which it was originally developed. Strictly, MOST requires horizontal homogeneity, stationarity and negligible influence of processes occurring above the surface layer (Katul et al., 2008; Moene and Schüttemeyer, 2008). Even over ideal surfaces, there are evidently times when MOST requirements are not fulfilled, simply due to the diurnal cycle. During strongly stable conditions weak turbulence, intermittency and the shallowness of the boundary layer create problems for observations (Hartogensis et al., 2002). Complex environments increase the probability that 'other' processes will be significant enough to affect behaviour, such as horizontal advection, non-local circulations, drainage flows or dissimilar scalar transport due to the distribution of sources and sinks (De Bruin et al., 1999; Katul et al., 2006; Moene and Schüttemeyer, 2008). Obstacles distort the flow and abrupt changes in surface characteristics generate internal boundary layers, which may make representative measurements difficult to conceptualise, let alone obtain. The challenge is to identify these processes and account for their effects on measurements.

A relevant, if controversial, concept is the blending height, $z b$, (Wieringa, 1993), which describes the height above which turbulent signatures of a heterogeneous surface are assumed to be blended together and the atmosphere is horizontally homogeneous. Providing a scintillometer can be installed close to or above $z_{b}$, and well below the height of the boundary layer, many of the complexities associated with heterogeneous surfaces are assumed to be resolved. Various methods exist for estimating $z_{b}$ (e.g., Pasquill, 1974; Garratt, 1978; Wood and Mason, 1991). Typical values are of the order of some tens of metres for urban areas (Grimmond and Oke, 1999), are lower for small agricultural fields and increase with the scale of heterogeneity. If the scale of heterogeneity approaches the boundary-layer height, the blending height may not exist at all (Maronga and Raasch, 2013). Using LES, Maronga et al. (2014) indicated clear horizontal variation in $C_{T}{ }^{2}$ and $C_{q}{ }^{2}$ up to heights of 100-200 m over heterogeneous farmland with patches $0.5-1.0 \mathrm{~km}$ in scale. It is not currently known how the blending height for fluxes might relate to a blending height for structure parameters (Beyrich et al., 2012). Many studies have used the blending height concept to (often vaguely) explain why reasonable fluxes appear to be obtainable in complex environments. There is little evidence, however, that findings are substantially different below $z_{b}$ (e.g. Chehbouni et al., 2000; Lagouarde et al., 2002), whereas at greater heights, flux divergence and entrainment can become problematic and measurements made above the surface layer usually cannot be related to surface fluxes (Braam et al., 2012). 


\subsubsection{Similarity functions}

Similarity functions most relevant to scintillometry are those relating structure parameters to surface fluxes (Eq 7). These semi-empirical relations always include moderate scatter even with the highest quality data over homogeneous surfaces. Provided measurements are above the roughness sublayer, the complexity of the site does not appear to preclude the use of MOST, rather the issues are with the MOST approach itself. Under neutral and stable conditions, MOST relations are less welldefined and less successful.

Even for homogeneous surfaces the lack of consensus around similarity functions has led to substantial uncertainty. Commonly applied functions are An88 and DB93, although various formulations exist (Figure 4). DB93 tends to give 10-15\% larger fluxes than An88 (Lagouarde et al., 2006; Beyrich et al., 2012; Ward et al., 2014). Savage (2009) gives a detailed comparison of several similarity functions for stable and unstable conditions from an extensive 30-month SLS dataset collected over mixed grassland. Comparisons are made relative to the Thiermann and Grassl (1992) (TG92) functions as these gave the closest agreement with EC data. Taking TG92 as the reference, differences of up to $\pm 30 \%$ were found for unstable conditions. For stable conditions relative differences are much higher (as $Q_{H}$ is small) but absolute differences of up to $60 \mathrm{~W} \mathrm{~m}^{-2}$ were found. Note TG92 gives smaller fluxes than many of the other options (except for Hill et al. (1992) (Hi92) for neutral conditions - in Figure 4 the TG92 line is higher than the others). Several studies select one set of functions (perhaps guided by consideration of the measurement setup and conditions) and briefly illustrate how their choice affects the fluxes. In some cases, the choice may change the conclusions (from $Q_{H_{-} s c} \approx Q_{H_{-} E C}$ to $Q_{H_{-} s c}>Q_{H_{-} E C}$ ). Meijninger et al. (2006) averaged fluxes calculated using An88 and DB93 and used the difference as the uncertainty. The advantage of this approach is that it partially avoids subjective selection of a particular similarity function.

Observed $C_{T}^{2}$ scaling has been compared to existing functions in the literature for homogeneous (e.g., De Bruin et al., 1993; Hartogensis and De Bruin, 2005; Li et al., 2012), heterogeneous (Hoedjes et al., 2007; Liu et al., 2011; Liu et al., 2013) and urban (Ward et al., 2015a; Zhang and Zhang, 2015) environments. Plotting dimensionless structure parameters as a function of stability (as in Figure 4) is often used to demonstrate the applicability of MOST at a particular site. However, since the expectation is for considerable scatter and possibly a deviation towards neutral conditions, it is often difficult to make an informative assessment. Furthermore, because $T_{*}$ is used both to make $C_{T}^{2}$ dimensionless (y-axis) and to calculate $L_{O b}$ (x-axis), spurious correlations can give misleading results (Hicks, 1981) so the reliability of the fluxes should also be verified (De Bruin et al., 1993).

Because it is easier to measure, the majority of studies focus on temperature and, in accordance with MOST, humidity is assumed to behave similarly. Differences between the scaling of $T$ and $q$ variances have been observed (e.g., Katul et al., 1995; Andreas et al., 1998), but the scaling of $C_{q}{ }^{2}$ has only been experimentally investigated in a few cases. Li et al. (2012) found similar behaviour for $T$ and $q$ over homogenous (lake and glacier) surfaces for unstable and stable conditions, but differences for weakly unstable conditions when surface fluxes are small and larger-scale processes which affect $T$ and $q$ differently become more significant (e.g., entrainment, advection). Data collected during the LITFASS-2009 campaign also indicate broadly similar behaviour for $T$ and $q$ in unstable conditions (Braam et al., 2014b), but less so in the near-neutral range. Using LES, Maronga et al. (2014) found the entrainment flux was too large to enable fitting of a similarity relation for $C_{q}{ }^{2}$ at all. Very slightly different relations were found for $C_{T}^{2}$ over the heterogeneous landscape compared to the homogeneous case. For two-wavelength scintillometry, identical similarity functions have always been assumed for temperature and humidity (Meijninger et al., 2006; Beyrich et al., 2012; Ward et al., 
2015a). If distinct $T$ and $q$ functions are deemed necessary, wider implications for the technique will also have to be considered.

In near-neutral conditions $C_{T}^{2}$ scaling is often seen to diverge. In neutral conditions resulting from small heat fluxes (rather than large shear stress) both $\left(z_{m}-z_{d}\right) / L_{O b}$ and $T *$ are small. Large uncertainties are associated with these data, but they have tended to distort the fit in the near-neutral range. Similar behaviour is not seen for humidity, as small $q_{*}$ does not necessarily occur under neutral conditions.

Recently, two detailed and extremely useful studies have made a significant contribution to this topic. Braam et al. (2014a) analyse similarity functions for $C_{T}^{2}$ and demonstrate that empirically-fitted coefficients are affected by the regression approach and the height and stability conditions for which the observations were made. They highlight the need for a more consistent and documented approach in future, and suggest using a regression approach that accounts for uncertainties in $\left(\mathrm{zm}^{-}\right.$ $\left.z_{d}\right) / L_{O b}$ and giving lower weight to unreliable data points. Kooijmans and Hartogensis (2016), hereafter $\mathrm{KH} 16$, combine measurements from eleven different datasets to define robust similarity functions for $C_{T}^{2}, C_{q}^{2}$ and $\epsilon$ over a wide range of stability. Following rigorous processing and quality control, errorweighted similarity functions are fitted. This minimises the influence of non-local effects and, in particular, the divergence as $T *$ becomes small. Functions are fitted to all data together and for the individual datasets. Different functions emerge from the individual datasets, especially those spanning a small stability range, leading to the conclusion that MOST functions cannot be adequately determined from a single dataset. Thus, together, these two key studies provide explanations for the variation in the literature. As a result of their rigorous analysis, $\mathrm{KH} 16$ are able to provide a new set of coefficients (following the Wyngaard et al. (1971) functional form) and reduce the uncertainty in $Q_{H}$ from about $10-20 \%$ to $6 \%$ (Figure 4). Compared to An88 and DB93, the $\mathrm{KH} 16 C_{T}^{2}$ function has a larger neutral limit, which will act to reduce the often observed overestimation of $Q_{H}$ under these conditions. Because this is the most complete and thorough derivation of these similarity functions to date, it is recommended that the $\mathrm{KH} 16$ functions and uncertainty estimates are used in future. As the $\mathrm{KH} 16$ datasets were all collected between 2-4 m over vegetated surfaces, and Braam et al. (2014a) showed similarity functions depend on measurement height, systematic investigation should be continued at greater measurement height and over urban surfaces.

Within the roughness sublayer standard forms of similarity functions are not expected to apply. Instead, alternative scaling relations using locally-derived coefficients can be used (Rotach, 1993; Roth, 1993), see dashed lines in Figure 4. To calculate fluxes from SLSs in the roughness sublayer, Kanda et al. (2002) and Roth et al. (2006) both derived 'urban forms' of the similarity functions from EC data (denoted $\mathrm{KaO2}$ and Ro06 respectively). Ka02 is reasonably similar to An88 and DB93, whilst Ro06 deviates towards neutral conditions, approaching a much larger constant value, similar to TG92 (Figure 4). The limitation of this approach is that the local scaling relation cannot be generalised, so relations derived for one site are not necessarily appropriate for another. Reassuringly, measurements at the COSMO field site revealed that within the roughness sublayer the similarity scaling is similar to the Ro06 'canyon' functions whereas above the roughness sublayer the scaling is similar to the TG92 'rural' reference (Sugawara et al., 2016). 


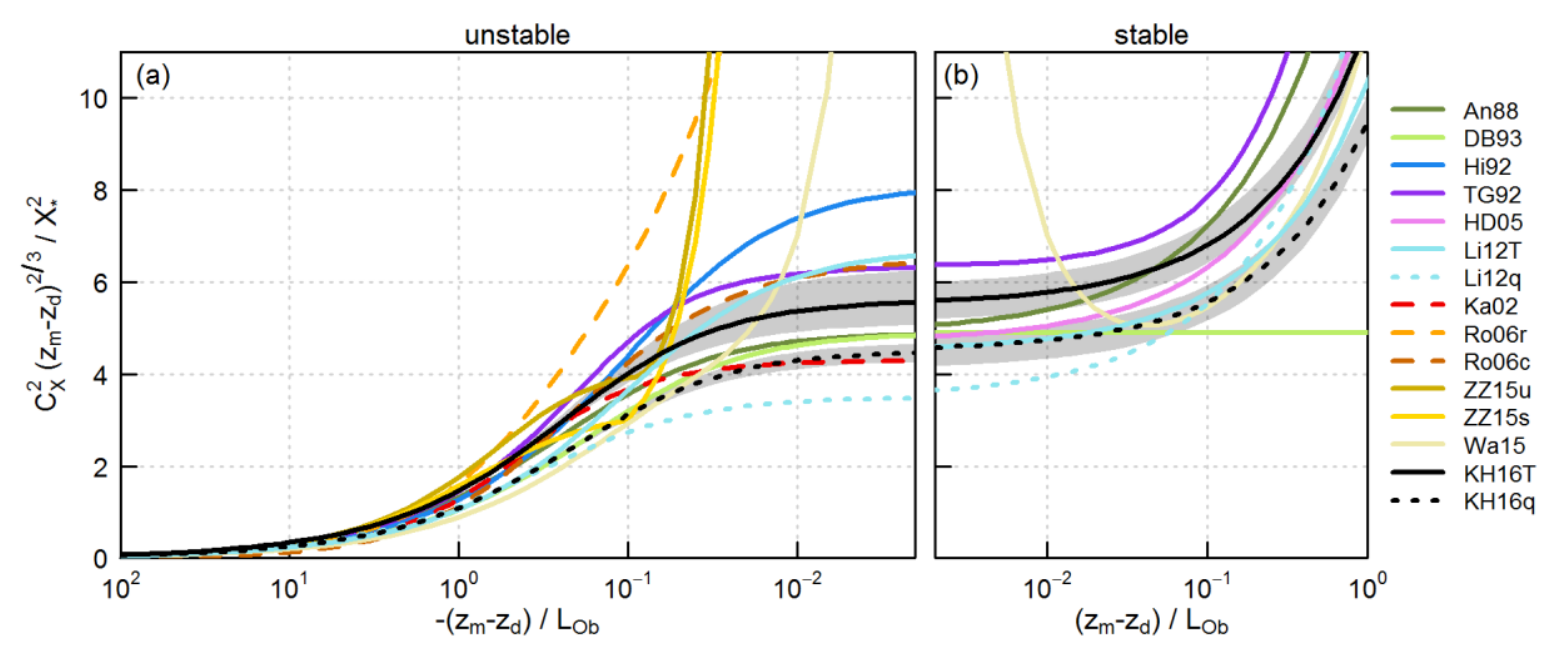

Figure 4: Monin-Obukhov similarity functions according to: An88 (Andreas, 1988); DB93 (De Bruin et al., 1993); Hi92 (Hill et al., 1992); Li12 (Li et al., 2012) and KH16 (Kooijmans and Hartogensis, 2016) for temperature (T) and humidity (q); TG92 (Thiermann and Grassl, 1992); HD05 (Hartogensis and De Bruin, 2005); Ka02 (Kanda et al., 2002); Ro06 (Roth et al., 2006) for rooftop ( $r$ ) and canyon (c); ZZ15 (Zhang and Zhang, 2015) for urban (u) and suburban (s); Wa15 (Ward et al., 2015a). Shading indicates the uncertainty range given in $\mathrm{KH} 16$.

\subsubsection{Temperature-humidity correlation}

Correlation between scalars is often used as a measure of MOST applicability. If MOST applies, perfect correlation or anti-correlation $\left(r_{T q}= \pm 1\right)$ is expected and $T$ and $q$ have identical similarity functions (Hill, 1989). However, studies measuring $r_{T q}$ over a variety of surfaces tend to find positive values close to but less than +1 under unstable conditions and smaller negative values under stable conditions (Table 1). Hence, even over ideal surfaces, $r_{T q}$ measurements suggest MOST is violated to some extent and over complex surfaces MOST does not appear to be violated as expected. Note, however, observations in more complex areas have tended to occur in more recent years, with better instrumentation, data logging capabilities and processing. Ideally, control experiments at homogeneous sites should be performed using the same apparatus and processing.

A few studies have observed clear diurnal cycles of $r_{T q}$ (Andreas et al., 1998; Beyrich et al., 2005), including shorter day length in winter months (Ward et al., 2015b). Analysis of temperature-humidity co-spectra can be useful for gaining further insight into the scales and processes affecting the transport of these scalars (e.g. Li et al., 2012). Andreas et al. (1998) investigated the effect of metrescale heterogeneity in vegetation (on variances) and found that whilst sources of moisture are patchy and $q$-scaling deviates from MOST, sources of heat appear to be homogeneous and $T$ scales according to MOST. Similarly, Katul et al. (1995) found that heat sources seem to be more uniform than moisture sources at three different sites, and hypothesise that this results from fairly uniform solar irradiance which is the primary driver of surface heating. Their data suggest the impact of heterogeneity varies with stability, being greater in near-neutral conditions.

Use of the bichromatic correlation technique to obtain $r_{T q}$ from scintillometry has been shown to give comparable results to fast-response (EC) sensors (Beyrich et al., 2005; Lüdi et al., 2005; Ward et al., 2015b). Values typically between 0.7 and 0.9 were obtained during daytime although experimental uncertainties lead to some non-physical values of $\left|r_{T q}\right|>1$ (Lüdi et al., 2005; Ward et al., 2015b). Despite the uncertainties, path-averaged $r_{T q}$ from the bichromatic method can help inform about the relative sign of the heat fluxes and whether $C_{T}^{2}$ scaling can be assumed to apply to $C_{q}^{2}$. In theory, accurate $r_{T q}$ improves structure parameters (and hence fluxes), although due to the high variability of bichromatic $r_{T q}$, the two-wavelength method has been used to derive fluxes (Meijninger et al., 2006; 
Ward et al., 2015a). For the two-wavelength method, assuming $r_{T q} \approx \pm 0.8$ will usually be more appropriate than \pm 1.0 .

\begin{tabular}{|c|c|c|c|c|}
\hline Reference & Location & Site description & $r T q$ & Comments \\
\hline Kohsiek (1982) & $\begin{array}{l}\text { Table Mountain, } \\
\text { Colorado }\end{array}$ & $\begin{array}{l}\text { Flat homogeneous } \\
\text { grassland }\end{array}$ & 0.75 average. & \\
\hline Hill et al. (1988) & Flatville, Illinois & $\begin{array}{l}\text { Flat homogeneous } \\
\text { agriculture }\end{array}$ & -0.99 to 0.98 & \\
\hline $\begin{array}{l}\text { De Bruin et al. } \\
\text { (1993) }\end{array}$ & La Crau, France & $\begin{array}{l}\text { Flat homogeneous } \\
\text { grassland }\end{array}$ & $\begin{array}{l}0.0 \text { to } 1.0 \text { (unstable), } \\
\text { typical values } 0.7 \text { to } 0.8 \text {. }\end{array}$ & $r_{T q}$ 'significantly smaller than $1^{\prime}$. \\
\hline Roth (1993) & $\begin{array}{l}\text { Vancouver, } \\
\text { Canada }\end{array}$ & $\begin{array}{l}\text { Suburban } \\
\text { residential }\end{array}$ & 0.2 to 0.8 (unstable). & No variation with stability. \\
\hline Katul et al. (1995) & $\begin{array}{l}\text { Maine; California; } \\
\text { North Carolina }\end{array}$ & $\begin{array}{l}\text { Mixed forest; } \\
\text { uniform bare soil; } \\
\text { grass field }\end{array}$ & -0.6 to 0.9 & $\begin{array}{l}r_{T q} \text { smaller than } 1 \text { and more } \\
\text { variable in neutral conditions. }\end{array}$ \\
\hline $\begin{array}{l}\text { Andreas et al. } \\
\text { (1998) }\end{array}$ & $\begin{array}{l}\text { Sevilleta, New } \\
\text { Mexico }\end{array}$ & $\begin{array}{l}\text { Sandy soil with } \\
\text { patchy vegetation; } \\
\text { metre-scale } \\
\text { heterogeneity }\end{array}$ & $\begin{array}{l}-0.9 \text { to } 0.9 ; \text { typical } \\
\text { magnitude } 0.76 \text {. }\end{array}$ & $\begin{array}{l}\text { Diurnal cycle with negative } \\
\text { values at night and positive } \\
\text { during the day. }\end{array}$ \\
\hline $\begin{array}{l}\text { De Bruin et al. } \\
\text { (1999) }\end{array}$ & $\begin{array}{l}\text { Wageningen, The } \\
\text { Netherlands }\end{array}$ & Flat, short grass & $\begin{array}{l}0.7 \text { to } 0.9 \text { during } \\
\text { daytime, }-0.5 \text { to }-0.9 \\
\text { during evening. }\end{array}$ & $\begin{array}{l}\text { Example day showing positive } \\
\text { values during the day and } \\
\text { negative in the evening. }\end{array}$ \\
\hline $\begin{array}{l}\text { Meijninger et al. } \\
(2002 a)\end{array}$ & $\begin{array}{l}\text { Flevoland, The } \\
\text { Netherlands }\end{array}$ & $\begin{array}{l}\text { Flat } \\
\text { heterogeneous } \\
\text { agriculture }\end{array}$ & 0.70 to 0.95 (unstable). & \\
\hline $\begin{array}{l}\text { Beyrich et al. } \\
\text { (2005); Lüdi et al. } \\
\text { (2005) }\end{array}$ & $\begin{array}{l}\text { LITFASS region, } \\
\text { Germany }\end{array}$ & $\begin{array}{l}\text { Heterogeneous } \\
\text { agriculture }\end{array}$ & $\begin{array}{l}\text { Typically } 0.7 \text { to } 0.9 \text { during } \\
\text { daytime and }-0.8 \text { at night. } \\
\text { Bichromatic method } \\
\text { gives } 0.8 \text { for large } \beta \text {. }\end{array}$ & $\begin{array}{l}\text { Uncertainties in bichromatic } \\
\text { method give some values larger } \\
\text { than } 1 . \\
\text { Diurnal cycle with negative } \\
\text { values at night and positive } \\
\text { during the day. }\end{array}$ \\
\hline $\begin{array}{l}\text { De Bruin et al. } \\
\text { (2005) }\end{array}$ & Idaho & $\begin{array}{l}\text { Irrigated } \\
\text { agricultural fields } \\
\text { surrounded by } \\
\text { desert }\end{array}$ & $\begin{array}{l}\text { Ranges between }-1 \text { and } \\
+1 \text {. }\end{array}$ & $\begin{array}{l}\text { Negative values for advection } \\
\text { conditions }\left(Q_{H}<0 \mathrm{~W} \mathrm{~m}^{-2}\right)\end{array}$ \\
\hline $\begin{array}{l}\text { Lamaud and Irvine } \\
\text { (2006) }\end{array}$ & $\begin{array}{l}\text { Landes forest, } \\
\text { France }\end{array}$ & $\begin{array}{l}\text { Above and within } \\
\text { pine forest canopy }\end{array}$ & $\begin{array}{l}\text { Mostly } 0.50 \text { to } 0.95 \\
\text { (median } 0.75 \text { ) above } \\
\text { canopy, mostly } 0.40 \text { to } \\
0.80 \text { (median } 0.70 \text { ) below } \\
\text { canopy; many low values. }\end{array}$ & $\begin{array}{l}\text { No variation with stability } \\
\text { (unstable conditions). Varies } \\
\text { with } \beta \text {. }\end{array}$ \\
\hline Li et al. (2012) & $\begin{array}{l}\text { Lake Geneva, } \\
\text { Switzerland; } \\
\text { Pleine Morte } \\
\text { glacier, } \\
\text { Switzerland }\end{array}$ & $\begin{array}{l}\text { Homogeneous } \\
\text { lake; } \\
\text { homogeneous } \\
\text { glacier }\end{array}$ & $\begin{array}{l}\text { Magnitude close to } 1.0 \text { in } \\
\text { stable and neutral } \\
\text { conditions; close to } 0.9 \text { in } \\
\text { unstable conditions; } \\
\text { smaller values for weakly } \\
\text { unstable conditions. }\end{array}$ & $\begin{array}{l}r_{T q} \text { reduces under weakly } \\
\text { unstable conditions. }\end{array}$ \\
\hline $\begin{array}{l}\text { Ward et al. } \\
\text { (2015b) }\end{array}$ & Swindon, UK & $\begin{array}{l}\text { Suburban } \\
\text { residential }\end{array}$ & $\begin{array}{l}\text { Typical values: } 0.6 \text { to } 0.9 \\
\text { (unstable); }-0.5 \text { to }-0.3 \\
\text { (stable). }\end{array}$ & $\begin{array}{l}\text { Uncertainties in bichromatic } \\
\text { method give some values larger } \\
\text { than } 1 . \text { Diurnal cycle with } \\
\text { negative values at night and } \\
\text { positive during the day. Width } \\
\text { of diurnal cycle varies with } \\
\text { season. }\end{array}$ \\
\hline
\end{tabular}

Table 1: Observed temperature-humidity correlation for various sites.

\subsubsection{Advection}

As scintillometers are sensitive to $T$ (or $q$ ) fluctuations (whether or not the fluctuations are correlated with vertical wind speed), they are not thought to distinguish between surface and advective fluxes and therefore the 'surface' fluxes derived may be overestimated if the advection contribution is significant. However, this has not been experimentally demonstrated. Hoedjes et al. (2002) investigated scintillometry in advective conditions by deploying a LAS over an irrigated wheat 
field in a semi-arid region. EC measurements showed large $Q_{E}$ (often exceeding $500 \mathrm{~W} \mathrm{~m}^{-2}$ ), whilst $Q_{H}$ was small (often below $75 \mathrm{~W} \mathrm{~m}^{-2}$ ) and became negative in the afternoons $\left(-20\right.$ to $-60 \mathrm{~W} \mathrm{~m}^{-2}$ ) as energy from warm air was used in evapotranspiration. For stable and unstable conditions, scaling relations for $C_{T}^{2}$ were generally followed, although data points were above the theoretical curve for both irrigated and dry unstable conditions. Agreement between EC heat fluxes and scintillometer heat fluxes was very good, with most scatter for $Q_{H}$ in stable conditions. However, the Bowen ratio closure method (Twine et al., 2000) was used to adjust EC fluxes, so it is not obvious how to interpret these results. The observed overestimation in $C_{T}^{2}$ scaling may be due to underestimation in $T *$ (which was not corrected for energy closure); entrainment of dry desert air that advected over the shallow humid internal boundary layer over the irrigated field; and surface heterogeneity in the surrounding fields.

Sensible heat fluxes from a LAS deployed along a beach were found to exhibit large changes throughout the day, as the circulation pattern changed from seaward (scintillometer footprint located over land) to landward (footprint over sea) and cold or warm air was advected across the alternate surface (Lee, 2015). The major change in footprint composition, and lack of comparison dataset, means it is difficult to infer details about the effect of advection from this study, and how it might impact the fluxes. A more controlled study of micro-scale advection, such as at the boundary of irrigated urban parks (Spronken-Smith et al., 2000), may offer interesting insights into the capabilities and limitations of scintillometry.

\subsection{Scintillometer footprints}

Footprint calculations have enabled substantial advances in evaluation of scintillometer performance over heterogeneous terrain (Section 3.1), as well as ensuring comparisons with remote sensing data or model output are representative of compatible areas. Note that since scintillometers measure structure parameters, source area calculations based on fluxes may not be the correct approach. The error is likely to be small compared to other uncertainties involved in footprint estimation (such as their use in heterogeneous conditions), but understanding more about the behaviour of structure parameters in relation to footprints is an important task.

Scintillometer source areas can extend over several square kilometres. They are largest for winds perpendicular to the path but for winds parallel to the path the footprint is much smaller (Meijninger et al., 2002b). In contrast to EC, a change in wind direction alone can therefore produce a substantial change in the size of the scintillometer source area and thus affect the statistical nature of the results. It is generally advisable to install scintillometers so that the path is not aligned with the prevailing wind. Footprint modelling can be used to inform path selection and check measurements will be representative of the desired study area.

\subsection{Obtaining accurate input information}

\subsubsection{Effective measurement height}

When the height of the scintillometer beam is not constant along the path (slanted paths and/or when the underlying topography varies along the path) an effective height, $z_{e f}$, should be used (Hartogensis et al., 2003). $z_{e f}$ is a single path-weighted value that represents the height of the $C_{n}{ }^{2}$ measurement. It is calculated from the beam height at position $x$ along the path, $z_{m}(x)$, obtained from topographic maps (e.g., De Bruin et al., 1995; Evans et al., 2012) or digital terrain models (e.g., Ward et al., 2014). The displacement height is usually incorporated in the effective height calculation, so $z_{e f}$ replaces $\left(z_{m}-z_{d}\right)$ in Eq 7 .

Several approximations for $z_{e f}$ are given in Hartogensis et al. (2003), but slightly better results were obtained when the full stability-dependent estimation is used. LAS fluxes for a horizontal path (of 
length $1100 \mathrm{~m}$ ) agreed better with EC than for a slanted path (of length $3200 \mathrm{~m}$ ), although absorption and saturation are thought to have affected data for the longer path making a clear conclusion difficult. A short comparison of SLSs on a horizontal path and a slanted path with five sonic anemometers at the same height suggested there is no significant deterioration in $u *$ and $Q_{H}$ obtained from slanted paths compared to level paths (Rotach et al., 2004; Rotach et al., 2008). This study, among others (Wood et al., 2013a; Lee et al., 2015), highlights the importance of accurate $z_{e f}$. The impact of inaccuracies in $z_{e f}$ can be reduced by maximising beam height.

For a two-wavelength scintillometer system, the situation is more complex because of the different path-weighting functions of the LAS and MWS. $C_{n}{ }^{2}$ from the MWS must first be scaled to the height of the LAS measurement using the ratio of the effective heights of the respective instruments (Evans and De Bruin, 2011). Structure parameters obtained subsequently are then representative of the LAS effective height.

\subsubsection{Roughness length and displacement height}

To calculate fluxes from long-path scintillometry an estimate of the roughness length is required to relate measured wind speed to friction velocity (Eq 6). Note, $z_{0}$ is not required to calculate structure parameters, if the free convection approximation is used, if an alternative measurement of $u_{*}$ representative of the scintillometer footprint is used (e.g., from a suitably located EC station), or to calculate the heat flux from SLSs (as $u *$ is obtained from the scintillometer).

Sensitivity analyses show that $z_{0}$ can have a major impact on the fluxes, particularly for rough surfaces and near-neutral conditions (Hartogensis et al., 2003; Beyrich et al., 2012). In urban areas zo is typically large and difficult to quantify, such that uncertainties are substantial. In Swindon, changing $z_{0}$ by $\pm 0.2 \mathrm{~m}$ changes the scintillometer fluxes by $\pm 7 \%$ (Ward et al., 2015a). In Marseille, a large range of $z_{0}(0.7-1.5 \mathrm{~m})$ based on typical values for similar urban areas translates to an uncertainty in the fluxes of between -6.0 and $9.2 \%$ (-4.2 and 6.3\%) for a wind speed measurement height of $37.9 \mathrm{~m} \mathrm{(43.9}$ $\mathrm{m})$ (Lagouarde et al., 2006). Hence the impact of uncertainties in $z_{0}$ can be reduced by using a higher wind speed measurement. This also helps to reduce the impact of individual obstacles on the measured $U$. Obtaining $u_{*}$ representative of the scintillometer path is challenging in complex environments. In Helsinki, Wood et al. (2013a) use $L_{O b}$ and $u *$ from a nearby sonic, thus removing the need to calculate $z_{0}$ for their urban paths, whereas Zieliński et al. (2013) opt for the iterative procedure to derive $u *$ for their path as surface characteristics differ between their two EC stations $\left(z_{0}=1.1\right.$ and $1.6 \mathrm{~m})$ and scintillometer path $\left(z_{0}=1.7 \mathrm{~m}\right)$.

The displacement height enters the calculations alongside the beam height (Eq 7) and is usually incorporated with $z_{e f}$. Therefore, uncertainties in $z_{d}$ impact the results in the same way as uncertainties in the measurement height. If uncertainties in $z_{d}$ are small compared to the measurement height, their impact will be small. However, for dense urban areas or forests, $z_{d}$ and the uncertainty in $z_{d}$ may be considerable and significantly impact the results (Lagouarde et al., 2006; Nakaya et al., 2006; Wood et al., 2013a).

In rural areas, vegetation surveys may be used to determine crop height from which $z_{0}$ and $z_{d}$ are estimated using published formulae (e.g., Ezzahar et al., 2007a). Alternatively, typical values from the literature (Evans et al., 2012) or from measurements on site (Kohsiek et al., 2006; Guyot et al., 2009) may be used. Aerodynamic parameters should be representative of the whole scintillometer footprint, rather than simply the area below the beam (Timmermans et al., 2009; Geli et al., 2012). For footprints comprising two or more patches with different aerodynamic properties, various aggregation schemes exist to combine $z_{0}$ and $z_{d}$ (Timmermans et al., 2009). Geli et al. (2012) examined the impact on scintillometer fluxes of using surface parameters calculated according to traditional methods 
(vegetation surveys) or using lidar data. The accurate lidar data improved results, however it should be noted that a single lidar dataset would not capture changes in time due to vegetation growth (De Bruin et al., 1995; Hoedjes et al., 2002) or building development.

Calculating $z_{0}$ and $z_{d}$ for urban areas remains a major challenge (Grimmond and Oke, 1999). The simple rules-of-thumb developed for vegetated canopies are often applied as a first-order estimate of $z_{0}=0.1 z_{H}$ and $z_{d}=0.7 z_{H}$, where $z_{H}$ is mean obstacle height (Garratt, 1992), but both parameters depend on the layout, orientation and type of obstacle (porous or bluff) and many different formulations can be found in the urban literature which attempt to account for these factors, incorporating additional information such as the frontal area index (Macdonald et al., 1998) or maximum and standard deviation of building height (Kanda et al., 2013). Lidar data or digital surface models are indispensable for these calculations as they provide detailed information about the size, shape and layout of buildings and vegetation which impact the aerodynamic parameters. To some extent, the larger size of LAS footprints helps to average out some of the variation at the neighbourhood-scale that can be seen in changing source area characteristics of EC measurements with wind direction (Nordbo et al., 2013; Kotthaus and Grimmond, 2014). Nevertheless, there will be substantial uncertainty associated with the estimated value, not due to the quality of input data but rather the absence of agreement as to the correct value. Kanda et al. (2002) calculate $z_{d}$ from SLS measurements at two heights in a dense residential area of Tokyo $\left(z_{H}=8.5 \mathrm{~m}\right)$. The scintillometerderived $z_{d}$ is $6.6 \mathrm{~m}$ on average, similar to the range of values obtained from morphometric methods (5.71-7.26 m), but the spread of values highlights the lack of a definitive approach. At the simpler COSMO test site, much closer agreement was found between techniques to estimate $z_{d}$ (Sugawara et al., 2016). In Helsinki, Wood et al. (2013a) use a value of $z_{d}$ calculated using the morphometric method of Macdonald et al. (1998). In China, Zhang and Zhang (2015) compute $z_{d}$ using the temperature variance method (Rotach, 1994) and $z_{0}$ following Chen et al. (1993). A practical approach is to estimate $z_{0}$ and $z_{d}$, then consider the impact on the heat fluxes introduced by the uncertainty in $z_{0}$ and $z_{d}$ (Lagouarde et al., 2006; Zieliński et al., 2013; Ward et al., 2014; Lee et al., 2015). These studies suggest that differences between the methods are large enough not to warrant excessively detailed computation of aerodynamic parameters using one particular method, as there is so much uncertainty as to the 'true' value.

Further complications arise when considering temporal changes. As leaf area affects the porosity of trees, $z_{0}$ in vegetated urban areas can be $10-20 \%$ smaller in winter than summer (Grimmond et al., 1998), although this is rarely accounted for in scintillometer studies. Nakaya et al. (2006) used a constant value of $z_{d}$ to process SLS data over a mixed deciduous forest but demonstrates clear differences in $u *$ and $Q_{H}$ between leaf-on and leaf-off periods. There is also evidence to suggest variations with stability (Zilitinkevich et al., 2008). Hoedjes et al. (2007) use a dynamic $z_{d}$ when calculating fluxes from LAS data in an olive orchard to account for the decrease in $z_{d}$ at high solar angles as radiation can penetrate deeper into the vegetation canopy. Compared to using a fixed value of $z_{d}$, the underestimation (overestimation) at high (low) $Q_{H}$ was reduced.

To summarise, $z_{0}$, $z_{e f}$ (and $z_{d}$ ) are important input parameters that can significantly impact scintillometer fluxes but can be very difficult to determine in complex environments. Accurate elevation information should be used to determine beam height, but for $z_{0}$ and $z_{d}$ it is recommended to make an informed estimate and consider the uncertainties. Increasing beam height reduces the impact of the uncertainties on the fluxes, however the scintillometer should still be located within the surface layer so that measurements can be related to surface fluxes (Braam et al., 2012). In urban areas, it can be a challenge ensuring measurements are high enough to be above the roughness sublayer, yet low enough that interference from fog, cloud or boundary-layer processes is minimised. 


\subsubsection{Representative meteorological data}

Although basic meteorological variables $(T, R H, p$ and $U)$ are required to obtain structure parameters and fluxes, results are fairly insensitive to their values (Hartogensis et al., 2003; Savage, 2009). Errors in $U$ are generally small but can be important in neutral conditions. Therefore, using meteorological data from a single (albeit suitably sited) station should be sufficient to obtain reasonable fluxes, even in complex environments (Ward et al., 2014; Crawford et al., 2017).

\subsection{Surface energy balance considerations}

To calculate $Q_{H}$ from a single-wavelength scintillometer the Bowen ratio may be used to account for the influence of humidity fluctuations on $C_{n}{ }^{2}(\mathrm{Eq} 5)$ and to correct the Obukhov length for buoyancy (Eq 8). In homogeneous environments, this can be achieved by incorporating measurements of net all-wave radiation $Q^{*}$ and the ground heat flux $Q_{G}$ into the iteration (e.g., Green and Hayashi, 1998). The residual of the energy balance $\left(Q_{E}=Q^{*}-Q_{G}-Q_{H_{-} s c}\right)$ is used to obtain $Q_{E}$ from a single-wavelength system.

For more complex sites, the same procedures can be used if representative values of $Q^{*}$ and $Q_{G}$ are available, usually obtained by aggregating measurements from several stations within the scintillometer footprint (Meijninger et al., 2002b; Evans et al., 2012). But at a hilly and highly heterogeneous vegetated site in Sri Lanka, only one radiometer was installed, which limited the accuracy of $Q_{E}$ since the source area was very small and shaded in the late afternoon by a nearby hill (Hemakumara et al., 2003).

In urban areas, the energy balance is far more complex (Oke, 1987):

$$
Q^{*}+Q_{F}=Q_{H}+Q_{E}+\Delta Q_{S} .
$$

The net storage heat flux $\Delta Q_{S}$ is much larger than in most natural environments and very difficult to measure (Offerle et al., 2005; Roberts et al., 2006). The anthropogenic heat flux $Q_{F}$ is highly variable in space and time, also very difficult to observe directly and can be substantial, particularly for dense urban areas during winter (Sailor, 2011). Fortunately $\beta$ is often large enough in the urban environment that the correction term in Eq 5 is small enough to be safely neglected (Roth et al., 2006; Ward et al., 2014), as for several non-urban studies with large $\beta$ (Chehbouni et al., 2000). Lagouarde et al. (2006) used observed $Q^{*}$ and an estimate of $\Delta Q_{S}$ but concluded that errors in $\Delta Q_{S}$ had little impact because the dry summertime conditions in Marseille resulted in large $\beta$ anyway. Wood et al. (2013a) and Zieliński et al. (2013) use data from two EC towers in their respective study cities (Helsinki and Łódź) to apply the $\beta$ correction. The buoyancy correction to $L_{O b}$ is frequently neglected (e.g., Meijninger et al., 2002b; Wood et al., 2013a; Zieliński et al., 2013).

The complexity of the energy balance means estimation of $Q_{E}$ as the residual is generally not feasible in urban areas. (In Rotterdam, however, Jacobs et al. (2015) did calculate $Q_{E}$ as the energy balance residual during daytime, approximating the storage heat flux as $0.3 Q^{*}$ and neglecting $Q_{F}$.) Crawford et al. (2017) estimate monthly $Q_{E}$ in central London by comparing $Q_{H_{-} s c}$ for wet and dry conditions as a function of vegetation cover. In future, it is possible that improved capability to model $Q_{F}$ and $\Delta Q_{S}$ could enable more accurate estimates of these terms to be used in scintillometry calculations. This would certainly be useful if these fluxes could be modelled at the same scale as the scintillometer footprint. 


\subsection{Instrument sensitivity}

Infrared scintillometers, primarily sensitive to temperature fluctuations, are less reliable when $\beta$ is very small as the influence of water vapour fluctuations dominates. On the other hand, microwave scintillometers are not useful for $\beta \approx 2-3$ (Leijnse et al., 2007a; Ward et al., 2013) as the $C_{T q}$ term cancels the $C_{T}{ }^{2}$ and $C_{q}{ }^{2}$ terms (Eq 4), resulting in very small $C_{n}{ }^{2}$ and reduced system performance as the magnitude of the scintillation signal is comparable to the instrument noise floor. These issues are not confined to complex environments, however a microwave system in a sparsely vegetated unirrigated urban area may be of limited use if $\beta$ is large.

\subsection{Saturation}

Saturation occurs when turbulence is strong enough that the weak scattering assumption no longer applies and intensity fluctuations are no longer proportional to $C_{n}^{2}$ (e.g., Kohsiek et al., 2006; Kleissl et al., 2010). As the degree of saturation increases, measured fluctuations in beam intensity increase less and less with $Q_{H}$ so that measured $C_{n}{ }^{2}$ increasingly underestimates true $C_{n}{ }^{2}$. Whilst instrument specifications may give an upper limit to the operating range of around $5000 \mathrm{~m}$, the tendency for large $Q_{H}$ in urban areas (as a result of little vegetation cover and/or the additional energy supplied by anthropogenic activities) may mean the beam saturates short of this distance. Wood et al. (2013a) identified saturation for a $4.2 \mathrm{~km}$ path over Helsinki, for example. The risk of saturation can be reduced by using a shorter path, a higher path, or a larger aperture. To some extent, saturation can be corrected for using look-up-tables generated from theory (Clifford et al., 1974; Kleissl et al., 2010) but the uncertainty increases with increasing saturation. Of course, saturation may also be problematic in non-complex environments with high $Q_{H}$.

\subsection{Variable wind field}

Complex environments are often associated with spatially varying wind fields. Accurate structure parameter measurements should still be possible under these conditions (Ward et al., 2011), but methods to retrieve crosswind speed (the wind speed perpendicular to the beam) are generally adversely affected. Several methods have been developed to enable crosswind speed to be derived from scintillometry (Lawrence et al., 1972; Wang et al., 1981; Poggio et al., 2000; van Dinther et al., 2013). In the European Alps, Poggio et al. (2000) assessed various crosswind retrieval methods using five scintillometer paths and Furger et al. (2001) used scintillometers to measure vertical and horizontal crosswind components of foehn winds. Both studies found that significant spatial variability in the wind field has a detrimental impact on the crosswind retrieval. van Dinther et al. (2015b) were able to modify their look-up-table approach (van Dinther and Hartogensis, 2014) to adapt to variable wind conditions based on analysis with lidar data over the city of Helsinki.

In central London, Wood et al. (2013b) showed channelled airflow along the River Thames using crosswind from scintillometry and lidar. Such mechanisms for pollutant dispersion have important implications for air quality, particularly in cities, but are difficult to quantify with point measurements. Scintillometry has also been used to monitor crosswind speeds and detect wake vortices at airports (van Dinther et al., 2013; van Dinther et al., 2015a). Besides these applications, knowledge of the crosswind may be important for the quality of scintillometer data itself. Use of a dynamic bandpass filter has been suggested to account for the shift in frequency spectrum with crosswind (Solignac et al., 2012; Van Kesteren et al., 2015), as an inappropriate bandpass can artificially reduce $C_{n}{ }^{2}$. Whether related to the footprint, atmospheric conditions or basic principles of scintillometer measurement, it has been suggested that low and/or high crosswind speed has an impact on the accuracy of structure parameters and fluxes, particularly for two-wavelength systems (Evans, 2009; Ward et al., 2015b). Continued investigation of performance as a function of crosswind is expected to reveal improvements that should be implemented when processing scintillometer data. 


\subsection{Attenuation of the scintillometer beam}

Unobstructed line-of-sight is required for successful scintillometry application. Periods of interruption or attenuation of the beam by rain, fog, insects or poor air quality are usually removed during quality control. Yet it is also possible to relate signal intensity to visibility (Beyrich et al., 2002a; van Dinther et al., 2015a) and attenuation of microwave (Leijnse et al., 2007b) or infrared (Uijlenhoet et al., 2011) scintillometer beams can be converted to rainfall intensity, offering precipitation measurements at a valuable scale between that of point gauge sensors and radar. In urban areas, where precipitation can be very spatially variable, installing a scintillometer is far more practical than a dense network of rain gauges (Upton et al., 2005). Further development is required to reduce uncertainties (Leijnse et al., 2008), which would enable scintillometers to provide large-area observations of rainfall and fluxes together, particularly useful for hydro-meteorological monitoring. Although fluxes cannot be derived during rainfall, Ward et al. (2015a) presents high evaporation rates of intercepted water following rainfall using two-wavelength scintillometry. Further research including comparison with closed-path EC would be beneficial in understanding the capabilities and limitations of this method.

Absorption of the beam is associated with the imaginary part of the refractive index fluctuations (Nieveen et al., 1998), which must be excluded from the flux derivation usually by high-pass filtering (e.g., Lüdi et al., 2005) or using a dual-beam system (e.g., van Dinther et al., 2013). However, the imaginary part potentially contains useful information about turbulence (such as the outer length scale) and absorption and scattering by aerosols or trace gases. Yuan et al. (2015) used a LAS $(\lambda=0.62 \mu \mathrm{m})$ to investigate fluctuations in aerosol concentration at a university campus surrounded by busy roads in the city of Hefei, China, and subsequently extended the method to estimate aerosol mass flux using similarity theory (Yuan et al., 2016), although no direct evaluation was presented. Although several practical and theoretical uncertainties still require quantification, more routine analysis of the imaginary part of $C_{n}^{2}$ has potential.

Area-averaged fluxes of carbon dioxide have also been obtained from scintillometry by combining with point measurements of scalars (Van Kesteren et al., 2012; Van Kesteren et al., 2013). SLSs were used to obtain $u *$ and $L_{O b}$, which were combined with EC measurements of scalar turbulence statistics to yield field-scale latent heat and carbon dioxide fluxes at short timescales $(1 \mathrm{~min})$. These high temporal resolution data enabled investigation of non-stationary conditions and the response of vegetation to changes in light availability. Application of this new technique over more complex environments will be required to assess the importance of homogeneous conditions.

\section{Summary and outlook}

Over the last 20 years research has shown scintillometry to be a valuable technique for observing structure parameters and fluxes in complex (including urban) environments. Scintillometry offers several advantages, both practical and theory-based, compared to EC but importantly it should be seen as a complementary technique. Combining measurement techniques and being aware of their capabilities and limitations leads to a deeper understanding of observations and boundary-layer processes.

Scintillometer studies over heterogeneous surfaces provide surprisingly little evidence that MOSTrelated issues are more problematic than for homogeneous surfaces (Section 3). At ideal as well as complex sites, the applicability of MOST is limited when conditions are not favourable, which can happen for a number of reasons. Atmospheric conditions, instrumental setup, data processing and evaluation criteria (particularly choice of similarity function and variable of interest) can all affect the extent to which MOST is judged to apply or not apply. Even when scintillometers are installed in 
heterogeneous environments below the blending height, the general consensus is that reasonable fluxes are obtained, at least for unstable conditions. Further investigation is required particularly for near-neutral and stable conditions, and for humidity. But this requirement extends beyond scintillometry and applies to ideal surfaces as well.

So although careful consideration must be given to measurements in complex environments, contrary to expectations these areas do not seem to present overwhelming difficulties for scintillometry. Various tools have been developed to handle the added complexity and improve data quality and interpretation (Section 4). Footprint modelling is an extremely valuable tool for relating measurements to surface characteristics and, despite the uncertainties involved, has substantially advanced understanding of results and confidence in the technique. Footprints enable other datasets (from EC, remote sensing or modelling) to be made spatially compatible with the scintillometer, allowing dynamic aggregation of fluxes over heterogeneous areas and, in some cases, detailed explanation for differences between datasets through links to surface properties. Improvements to footprint models, particularly in complex environments, would be of great use to the flux community. Specifically regarding scintillometry, source area calculations for structure parameters, as opposed to fluxes, should be investigated.

Knowledge of the measurement footprint also enables better correspondence with source area characteristics. Accurately calculating the effective height is important, but even when highly detailed information about the surface geometry can be obtained, for complex surfaces the challenge remains as to how to translate this information into required aerodynamic parameters. Again, this topic has implications beyond scintillometry, but uncertainties in roughness length often contribute a sizeable uncertainty to scintillometer fluxes. In this respect, SLSs offer a distinct advantage in that they determine path-averaged friction velocity without $z_{0}$. It has been suggested that $u *$ and $l_{0}$ could be obtainable from LASs with a modified instrument design (Churnside et al., 1988; Moene et al., 2009).

Providing measurements are above the roughness sublayer and within the surface layer, MOST appears to be sufficiently applicable to permit use of similarity functions. The variety of functions available and lack of consensus - even for the homogeneous surface layer - has added substantial uncertainties and represents a major limitation of the technique. Thanks to two recent studies (Braam et al., 2014a; Kooijmans and Hartogensis, 2016), which took the much needed approach of systematically analysing large quantities of data to re-evaluate similarity functions, this situation may be markedly improved. They conclude that the variation between existing functions can be explained by the limited range of data and various data processing and analysis techniques. Using rigorous and well-documented procedures, new similarity functions are provided with reduced uncertainty estimates.

The fact that scintillometers measure structure parameters, rather than fluxes, does create a specific issue for scintillometer measurements over heterogeneous terrain, unrelated to MOST. The non-linearity between structure parameters and fluxes means scintillometers will tend to overestimate fluxes by a few percent (more so for $Q_{E}$ than $Q_{H}$ ) over patchy surfaces.

Although surface fluxes are often the desired quantity because they describe surface-atmosphere exchange, structure parameters are measured directly by the scintillometer and therefore avoid the uncertainties of similarity functions, roughness length and non-linear averaging. The usefulness of structure parameters should not be overlooked. Their analysis enables a more direct evaluation of scintillometer performance. Assimilation of $C_{T}^{2}$ or even $C_{n}^{2}$ into numerical models may be a promising route by which scintillometer networks could be used to improve weather prediction. 
Creating new links between scintillometry and models, satellite data and airborne campaigns should be a priority. Although these methods have their own limitations, they offer fresh perspective (and a different set of problems aside from the familiar EC limitations). Furthermore, scintillometers show great potential for helping to develop these other techniques, particularly for evaluating model output and satellite products (examples in Table 2). Further testing of two-wavelength systems to derive $Q_{E}$ would be highly beneficial for hydrological monitoring and agricultural applications, and for learning more about the similarity of temperature and humidity.

Besides fluxes and structure parameters, scintillometers can also yield crosswind, rainfall and visibility, and have been used to estimate fluxes of other species. These new developments offer exciting opportunities to extract a wealth of information from the basic scintillometer setup. It is also crucial to continue with fundamental research to ensure improvements in accuracy, reliability and interpretation. Future studies should focus on improved understanding of scintillometer observations for both ideal and non-ideal landscapes. Carefully designed field campaigns to understand scintillometer performance under various conditions significantly advance the field, leading to more informed quality control, a more robust approach to similarity functions, insight into temperaturehumidity similarity and additional tools or corrections to improve the accuracy and reliability of scintillometer measurements. Development of a standardised processing tool for scintillometer data (similar to those available for EC flux processing) would allow for greater consistency between studies and ensure recent developments in measurement theory are applied by the community. Considering the current rate of progress in sensor technology and data handling capabilities, the next 20 years offers great potential for further advances in scintillometry over a range of landscapes. 


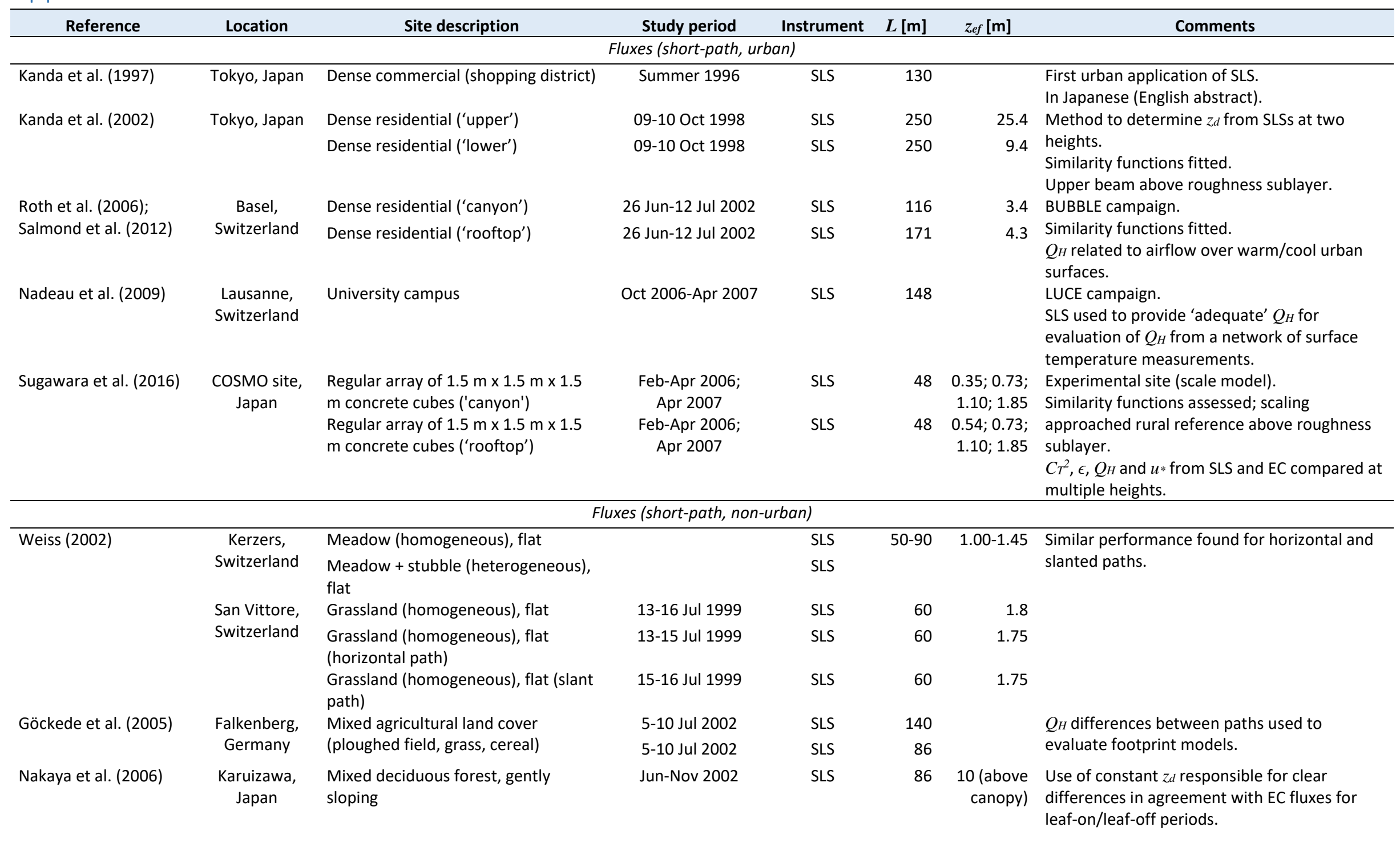




\begin{tabular}{|c|c|c|c|c|c|c|c|}
\hline Reference & Location & Site description & Study period & Instrument & $L[\mathrm{~m}]$ & $z_{e f}[\mathrm{~m}]$ & Comments \\
\hline Nakaya et al. (2007) & $\begin{array}{l}\text { Karuizawa, } \\
\text { Japan }\end{array}$ & $\begin{array}{l}\text { Mixed deciduous forest, gently } \\
\text { sloping }\end{array}$ & $\begin{array}{l}\text { Jun-Nov 2002; Jun- } \\
\quad \text { Nov } 2003\end{array}$ & SLS & 86 & $\begin{array}{r}10 \text { (above } \\
\text { canopy) }\end{array}$ & $\begin{array}{l}\text { SLS provides data that are more spatially } \\
\text { averaged than EC over mixed forest. }\end{array}$ \\
\hline \multirow{2}{*}{$\begin{array}{l}\text { Weiss et al. (2001); } \\
\text { Rotach et al. (2008) }\end{array}$} & \multirow{2}{*}{$\begin{array}{l}\text { Riviera Valley, } \\
\text { Switzerland }\end{array}$} & Mixed agriculture, valley floor & Aug-Oct 1999 & SLS & $50-200$ & & MAP-Riviera project. \\
\hline & & $\begin{array}{l}\text { Mixed agriculture, foot of slope } \\
\text { (gently sloping) }\end{array}$ & Aug-Oct 1999 & SLS & $50-200$ & & $\begin{array}{l}\text { Scintillometers can be used to investigate } \\
\text { surface energy balance in complex terrain. }\end{array}$ \\
\hline $\begin{array}{l}\text { Cammalleri et al. } \\
\text { (2010) }\end{array}$ & Sicily, Italy & Irrigated olive grove & 19 Jun-22 Sep 2007 & SLS & 95 & $5.8 \mathrm{agl}$ & $\begin{array}{l}Q_{E} \text { as energy balance residual used to evaluate } \\
\text { coupled energy/hydrologic model. }\end{array}$ \\
\hline \multicolumn{8}{|c|}{ Fluxes (long-path, urban) } \\
\hline \multirow[t]{3}{*}{ Lagouarde et al. (2006) } & \multirow[t]{3}{*}{$\begin{array}{l}\text { Marseille, } \\
\text { France }\end{array}$} & $\begin{array}{l}\text { Dense urban city centre (reasonably } \\
\text { homogeneous) ('PN') }\end{array}$ & 17 Jun-10 Jul 2001 & LAS & 1785 & $34.1-34.2$ & \multirow{3}{*}{$\begin{array}{l}\text { First urban application of LAS. } \\
Q_{H_{-} s c} \text { has smoother diurnal cycle than } Q_{H \_E C} \text {. } \\
\text { Uncertainties can be reduced with greater } \\
\text { measurement height. }\end{array}$} \\
\hline & & $\begin{array}{l}\text { Dense urban city centre (reasonably } \\
\text { homogeneous) ('PT') }\end{array}$ & 17 Jun-03 Jul 2001 & LAS & 1878 & 27.4-27.7 & \\
\hline & & $\begin{array}{l}\text { Dense urban city centre (reasonably } \\
\text { homogeneous) ('NT') }\end{array}$ & $04-10$ Jul 2001 & LAS & 2308 & $22.2-22.7$ & \\
\hline Masson et al. (2008) & $\begin{array}{l}\text { Toulouse, } \\
\text { France }\end{array}$ & $\begin{array}{l}\text { Old city centre ('relatively } \\
\text { homogeneous') }\end{array}$ & Mar 2004-Feb 2005 & LAS & 1833 & $\begin{array}{r}15-20 \\
\text { above roof } \\
\text { level }\end{array}$ & $\begin{array}{l}\text { Overview of CAPITOUL experiment. } \\
\text { No scintillometer results shown. }\end{array}$ \\
\hline Zieliński et al. (2013) & Łódź, Poland & $\begin{array}{l}\text { Dense urban city centre (reasonably } \\
\text { homogeneous) }\end{array}$ & Sep 2009-May 2012 & LAS & 3142 & $\approx 22$ & $\begin{array}{l}\text { Monthly diurnal cycles of } Q_{H} \text { from LAS } \\
\text { compared with two EC stations. } \\
\text { Fluxes calculated during night-time and } \\
\text { winter. }\end{array}$ \\
\hline \multirow[t]{2}{*}{ Wood et al. (2013a) } & \multirow{2}{*}{$\begin{array}{l}\text { Helsinki, } \\
\text { Finland }\end{array}$} & Urban, heterogeneous ('city-scale') & Jul 2011-Jun 2012 & LAS & 4200 & 33.6 & \multirow{2}{*}{$\begin{array}{l}\text { Analysis of } C_{T}^{2} \text { and } Q_{H} \text {. } \\
\text { City-scale path affected by saturation. }\end{array}$} \\
\hline & & $\begin{array}{l}\text { Dense urban, relatively } \\
\text { homogeneous ('downtown') }\end{array}$ & Mar 2012-Jun 2012 & LAS & 1840 & 48.3 & \\
\hline \multirow[t]{2}{*}{ Ward et al. (2014) } & \multirow[t]{2}{*}{ Swindon, UK } & Suburban residential & $\begin{array}{c}12 \text { Jan 2011-31 Dec } \\
2012\end{array}$ & LAS & 5492 & 45.0 & \multirow[t]{2}{*}{$\begin{array}{l}\text { Long path affected by saturation. } \\
\text { Seasonality and inter-annual variability in } Q_{H} \text {. }\end{array}$} \\
\hline & & & $\begin{array}{l}22 \text { Jun 2011-31 Dec } \\
2012\end{array}$ & LAS & 2761 & 35.9 & \\
\hline $\begin{array}{l}\text { Ward et al. (2015a); } \\
\text { Ward et al. (2015b) }\end{array}$ & Swindon, UK & Suburban residential & $\begin{array}{l}\text { Jul-Dec 2011; } \\
\text { May-Dec } 2012\end{array}$ & $\begin{array}{l}\text { LAS + MWS } \\
(94 \mathrm{GHz})\end{array}$ & 5492 & 45.0 & $\begin{array}{l}\text { First urban application of LAS-MWS. } \\
\text { Long-term trial of two-wavelength and } \\
\text { bichromatic method. } \\
Q_{H}, Q_{E}, C_{T}^{2}, C_{q}^{2}, r_{T q} \text { analysed. } \\
\text { Similarity functions assessed. }\end{array}$ \\
\hline Jacobs et al. (2015) & $\begin{array}{l}\text { Rotterdam, } \\
\text { The } \\
\text { Netherlands }\end{array}$ & Dense urban city centre & Jan-Dec 2012 & LAS & 3451 & 60 & $\begin{array}{l}Q_{E} \text { approximated as energy balance residual in } \\
\text { urban area (but not evaluated). }\end{array}$ \\
\hline Lee et al. (2015) & $\begin{array}{l}\text { Gongju, South } \\
\text { Korea }\end{array}$ & $\begin{array}{l}\text { Highly heterogeneous residential; } \\
\text { path crosses river }\end{array}$ & 11-12 Nov 2013 & LAS & 2100 & $25.1-27.2$ & $\begin{array}{l}\text { WRF simulations at } 200 \mathrm{~m} \text { averaged and } \\
\text { compared to } Q_{H} \text {. Simulations with and without } \\
\text { river show impact on night-time fluxes. }\end{array}$ \\
\hline
\end{tabular}




\begin{tabular}{|c|c|c|c|c|c|c|c|}
\hline Reference & Location & Site description & Study period & Instrument & $L[\mathrm{~m}]$ & $z_{e f}[\mathrm{~m}]$ & Comments \\
\hline $\begin{array}{l}\text { Zhang and Zhang } \\
\text { (2015); Zhang et al. } \\
\text { (2016) }\end{array}$ & $\begin{array}{l}\text { Changzhou, } \\
\text { China } \\
\text { Lishui, China }\end{array}$ & Urban & $10-20$ Jun 2012 & LAS & 440 & 33.0 & $\begin{array}{l}\text { Similarity functions fitted. } \\
\text { Wavelet analysis used to investigate large- } \\
\text { scale contributions to LAS and EC datasets. }\end{array}$ \\
\hline \multirow[t]{3}{*}{ Crawford et al. (2017) } & London, UK & Urban ('P1') & $\begin{array}{l}01 \text { Dec 2014-30 Nov } \\
2015\end{array}$ & LAS & 2358 & 111.6 & \multirow{3}{*}{$\begin{array}{l}\text { Spatial variation in } Q_{H} \text { using triangulated } \\
\text { paths. } \\
\text { Impact of anthropogenic activities evident in } \\
\text { differences with wind direction and between } \\
\text { weekdays/weekends. }\end{array}$} \\
\hline & & Urban ('P2') & $\begin{array}{c}01 \text { Dec 2014-30 Nov } \\
2015\end{array}$ & LAS & 3197 & 140.7 & \\
\hline & & Urban ('P3') & $\begin{array}{c}01 \text { Dec 2014-30 Nov } \\
2015 \\
\end{array}$ & LAS & 1097 & 98.7 & \\
\hline \multicolumn{8}{|c|}{ Fluxes (long-path, non-urban) } \\
\hline $\begin{array}{l}\text { Chehbouni et al. } \\
\text { (1999) }\end{array}$ & $\begin{array}{l}\text { Upper San } \\
\text { Pedro Basin, } \\
\text { Mexico }\end{array}$ & $\begin{array}{l}\text { Two-surface composite ( } 25 \% \text { grass + } \\
75 \% \text { mixed mesquite and grass) }\end{array}$ & $\begin{array}{l}7 \text { days in Jun, Jul, } \\
\text { Aug, Nov } 1997\end{array}$ & LAS & $\approx 900$ & 10.5 & \multirow{3}{*}{$\begin{array}{l}1997 \text { SALSA campaign. } \\
\text { Reasonable results in heterogeneous } \\
\text { environment. } \\
1998 \text { SALSA campaign. } \\
Q_{H_{-} E C} \text { and } Q_{H_{\_} s c} \text { compared for two patches } \\
\text { and aggregated values compared with } \\
\text { scintillometer spanning both patches. }\end{array}$} \\
\hline \multirow[t]{2}{*}{$\begin{array}{l}\text { Chehbouni et al. } \\
(2000)\end{array}$} & \multirow[t]{2}{*}{$\begin{array}{l}\text { Upper San } \\
\text { Pedro Basin, } \\
\text { Mexico }\end{array}$} & $\begin{array}{l}\text { Two-surface composite ( } 45 \% \text { grass + } \\
55 \% \text { mesquite) } \\
\text { Mesquite }\end{array}$ & 22 Sep-04 Oct 1998 & LAS & 1829 & 12.46 & \\
\hline & & Grass & 01 Oct-04 Oct 1998 & LAS & 826 & 6.14 & \\
\hline $\begin{array}{l}\text { Meijninger and De } \\
\text { Bruin (2000) }\end{array}$ & $\begin{array}{l}\text { Gediz Basin, } \\
\text { Turkey }\end{array}$ & $\begin{array}{l}\text { Mixed agriculture (grapes, cotton, } \\
\text { fruit trees), heterogeneous terrain }\end{array}$ & Apr-Oct 1998 & LAS & 2700 & 18 & \multirow{2}{*}{$\begin{array}{l}\text { Little discussion of heterogeneity. } \\
\text { Heterogeneity in crop height and land cover. } \\
\text { Simulations demonstrate non-linear averaging } \\
\text { effect in heterogeneous areas. } \\
\text { Possible influence of advection. }\end{array}$} \\
\hline Lagouarde et al. (2002) & $\begin{array}{l}\text { La Paillade, } \\
\text { France }\end{array}$ & $\begin{array}{l}\text { Two-surface composite }(67.6 \% \\
\text { wheat }+32.4 \% \text { bare soil) }\end{array}$ & 04-12 Jun 1997 & $\begin{array}{l}\text { LAS } \\
\text { LAS }\end{array}$ & $\begin{array}{l}667 \\
667\end{array}$ & $\begin{array}{l}2.05 \\
4.54\end{array}$ & \\
\hline Hoedjes et al. (2002) & $\begin{array}{l}\text { Yaqui Valley, } \\
\text { Mexico }\end{array}$ & $\begin{array}{l}\text { Irrigated wheat field; semi-arid } \\
\text { surroundings }\end{array}$ & 07 Jan-26 Apr 2000 & LAS & 758 & 3.4 & $\begin{array}{l}\text { Regional advection occurs: } Q_{H}<0 \mathrm{~W} \mathrm{~m}^{-2} \text { in } \\
\text { afternoon. } \\
\text { Similarity scaling assessed, some deviation in } \\
\text { near-neutral regime. }\end{array}$ \\
\hline $\begin{array}{l}\text { Meijninger et al. } \\
\text { (2002a); Meijninger et } \\
\text { al. (2002b) }\end{array}$ & $\begin{array}{l}\text { Flevoland, The } \\
\text { Netherlands }\end{array}$ & $\begin{array}{l}\text { Mixed agriculture (sugar beet, } \\
\text { wheat, potatoes, onions), flat }\end{array}$ & 18 Jul-20 Aug 1998 & $\begin{array}{l}\text { LAS + MWS } \\
(27 \mathrm{GHz})\end{array}$ & 2200 & $\begin{array}{r}11.6 \text { (LAS); } \\
10.9 \\
(\mathrm{MWS})\end{array}$ & $\begin{array}{l}\text { Detailed discussion of blending height. } \\
\text { Scintillometer footprint introduced. } \\
\text { Two-wavelength method used to obtain } Q_{H}\end{array}$ \\
\hline & & & 18 Jul-20 Aug 1998 & LAS & 2200 & 20.4 & $\begin{array}{l}\text { and } Q_{E} \text {. } \\
\text { Good agreement between aggregated EC and } \\
\text { scintillometer fluxes, even below } z b .\end{array}$ \\
\hline $\begin{array}{l}\text { Hemakumara et al. } \\
\text { (2003) }\end{array}$ & $\begin{array}{l}\text { Horana, Sri } \\
\text { Lanka }\end{array}$ & $\begin{array}{l}\text { Mixed vegetation (crops: coconut, } \\
\text { rubber; paddy; grasses; trees) }\end{array}$ & 23 Aug-28 Feb 2000 & LAS & 1940 & 83 & $\begin{array}{l}Q_{E} \text { from energy balance residual compared } \\
\text { with SEBAL. } \\
Q^{*} \text { measurements compromise accuracy. }\end{array}$ \\
\hline
\end{tabular}




\begin{tabular}{|c|c|c|c|c|c|c|c|}
\hline Reference & Location & Site description & Study period & Instrument & $L[\mathrm{~m}]$ & $z_{e f}[\mathrm{~m}]$ & Comments \\
\hline Min et al. (2004) & $\begin{array}{l}\text { Lezhi County, } \\
\text { China }\end{array}$ & Mixed agriculture and forest, hilly & $\begin{array}{l}16 \text { Apr } 2000-31 \text { Oct } \\
2001\end{array}$ & LAS & 2190 & 59.2 & $\begin{array}{l}\text { LAS used to derive aerodynamic surface } \\
\text { temperature for comparison with satellite } \\
\text { data. }\end{array}$ \\
\hline \multirow[t]{2}{*}{ Kohsiek et al. (2006) } & $\begin{array}{l}\text { Cabauw, The } \\
\text { Netherlands }\end{array}$ & Grassland ( $+7 \%$ built-up area), flat & $2002-2003$ & XLAS & 9800 & 43 & \multirow[t]{2}{*}{$\begin{array}{l}\text { Good agreement between } Q_{H_{-} s c} \text { and } Q_{H_{-} E C} a g g \\
\text { after substantial saturation correction. }\end{array}$} \\
\hline & $\begin{array}{l}\text { LITFASS } \\
\text { Region, } \\
\text { Germany }\end{array}$ & $\begin{array}{l}\text { Forest and patchy agricultural areas, } \\
\text { hilly }\end{array}$ & 21 May-18 Jun 2003 & XLAS & 10200 & 69.7 & \\
\hline \multirow{3}{*}{$\begin{array}{l}\text { Schüttemeyer et al. } \\
\text { (2006); Schüttemeyer } \\
\text { et al. (2007); Marx et } \\
\text { al. (2008) }\end{array}$} & Ejura, Ghana & $\begin{array}{l}\text { Dense mixed vegetation (cashew } \\
\text { trees, grass, maize, shrubs, swamp), } \\
\text { hilly }\end{array}$ & $\begin{array}{l}09 \text { Nov 2002-28 Jan } \\
2003\end{array}$ & LAS & 2030 & 30.1 & \multirow{3}{*}{$\begin{array}{l}\text { Analysis restricted to daytime (poor } \\
\text { agreement with EC at night). } \\
\text { Higher random errors at the more complex } \\
\text { site (Ejura), also linked to footprint overlap } \\
\text { and scale of heterogeneity. } \\
\text { Comparison of } Q_{H} \text { and } Q_{E} \text { from remote } \\
\text { sensing. }\end{array}$} \\
\hline & $\begin{array}{l}\text { Tamale, } \\
\text { Ghana }\end{array}$ & $\begin{array}{l}\text { Grassland with scattered trees, } \\
\text { slightly hilly }\end{array}$ & 03 Nov-15 Dec 2002 & LAS & 2420 & 19.5 & \\
\hline & $\begin{array}{l}\text { Navrongo, } \\
\text { Ghana }\end{array}$ & $\begin{array}{l}\text { Mixed (grass, baobab trees and } \\
\text { agricultural crops in wet season/bare } \\
\text { soil in dry season), nearly flat }\end{array}$ & $\begin{array}{l}\text { excluded from } \\
\text { analysis }\end{array}$ & LAS & 1040 & 12.8 & \\
\hline $\begin{array}{l}\text { Asanuma and lemoto } \\
\text { (2007) }\end{array}$ & $\begin{array}{l}\text { Kherlenbayan- } \\
\text { Ulaan, } \\
\text { Mongolia }\end{array}$ & $\begin{array}{l}\text { Grass + sparse agricultural land, non- } \\
\text { uniform terrain }\end{array}$ & 15 days Jul-Oct 2003 & LAS & $\begin{array}{r}1100 \\
1500 \\
3000 \\
4600\end{array}$ & $2.5-2.7$ & $\begin{array}{l}\text { Receiver position moved every day to capture } \\
\text { different surfaces. }\end{array}$ \\
\hline \multirow{2}{*}{$\begin{array}{l}\text { Ezzahar et al. (2007a); } \\
\text { Ezzahar et al. (2007b); } \\
\text { Hoedjes et al. (2007) }\end{array}$} & \multirow{2}{*}{$\begin{array}{l}\text { Agdal, } \\
\text { Morocco }\end{array}$} & Irrigated olive grove, north & 29 Sep-28 Nov 2002 & LAS & 1070 & 14.5 & \multirow{2}{*}{$\begin{array}{l}\text { Irrigation introduces soil moisture } \\
\text { heterogeneity. Footprint analysis and thermal } \\
\text { imagery used to explain differences between } \\
\text { LAS and EC data. } \\
\text { Similarity scaling assessed. }\end{array}$} \\
\hline & & Irrigated olive grove, south & $\begin{array}{l}29 \text { Sep 2002-27 Sep } \\
2004\end{array}$ & LAS & 1050 & 14.0 & \\
\hline Ezzahar et al. (2009b) & $\begin{array}{l}\text { Wankama } \\
\text { catchment, } \\
\text { Niger }\end{array}$ & $\begin{array}{l}\text { Mixed vegetation (shrubs, millet, } \\
\text { fallow) }\end{array}$ & 23 Jul-13 Aug 2006 & LAS & 3200 & & $\begin{array}{l}\text { Catchment-scale } Q_{E} \text { derived using LAS and } \\
\text { aggregated available energy scheme. }\end{array}$ \\
\hline \multirow[t]{3}{*}{ Ezzahar et al. (2009a) } & $\begin{array}{l}\text { Tensift Al } \\
\text { Haouz, } \\
\text { Morocco }\end{array}$ & $\begin{array}{l}\text { Irrigated olive yard ('Agdal'), } \\
\text { heterogeneous during irrigation } \\
\text { events }\end{array}$ & 31 Jul-31 Aug 2003 & LAS & 1050 & 14.0 & \multirow{3}{*}{$\begin{array}{l}\text { Large scatter between } Q_{H_{-} s c} \text { and } Q_{H_{-} E C} \text { during } \\
\text { irrigation events (heterogeneous conditions); } \\
\text { good agreement between events } \\
\text { (homogeneous conditions). }\end{array}$} \\
\hline & & $\begin{array}{l}\text { Irrigated wheat field ('R3'), } \\
\text { heterogeneous during irrigation } \\
\text { events }\end{array}$ & $\begin{array}{l}14 \text { Mar-23 May } \\
2003\end{array}$ & LAS & 690 & 4.5 & \\
\hline & & $\begin{array}{l}\text { Irrigated orange orchard ('Sâada'), } \\
\text { heterogeneous }\end{array}$ & 18 May-22 Jun 2004 & LAS & 500 & 9.2 & \\
\hline
\end{tabular}




\begin{tabular}{|c|c|c|c|c|c|c|c|}
\hline Reference & Location & Site description & Study period & Instrument & $L[\mathrm{~m}]$ & $z_{e f}[\mathrm{~m}]$ & Comments \\
\hline $\begin{array}{l}\text { Guyot et al. (2009); } \\
\text { Uijlenhoet et al. (2011) }\end{array}$ & $\begin{array}{l}\text { Donga } \\
\text { catchment, } \\
\text { Benin }\end{array}$ & $\begin{array}{l}\text { Mixed vegetation (shrubs, woodland, } \\
\text { crops/bare soil), variable topography }\end{array}$ & Feb-Apr 2006 & LAS & 2400 & $\begin{array}{r}18.35- \\
19.00\end{array}$ & $\begin{array}{l}\text { Zef varies with wind direction due to vegetation } \\
\text { height. } \\
Q_{E} \text { estimated as energy balance residual } \\
\text { assessed relative to energy and water budget. } \\
\text { Rainfall estimated from LAS. }\end{array}$ \\
\hline Kleissl et al. (2009) & New Mexico & Various & $2005-2009$ & LAS & $\begin{array}{r}606- \\
3388\end{array}$ & $17.6-62.9$ & $\begin{array}{l}\text { Network of } 7 \text { LASs to support remote sensing } \\
\text { and model evaluation. }\end{array}$ \\
\hline $\begin{array}{l}\text { Timmermans et al. } \\
\text { (2009) }\end{array}$ & Barrax, Spain & $\begin{array}{l}\text { Partly irrigated agriculture (various } \\
\text { crops/bare soil), flat }\end{array}$ & $12-21 \mathrm{Jul} 2004$ & LAS & 784 & 4.85 & $\begin{array}{l}\text { Assessment of area-averaged input } \\
\text { parameters for scintillometer footprint. }\end{array}$ \\
\hline \multirow{3}{*}{$\begin{array}{l}\text { Bai et al. (2009); Jia et } \\
\text { al. (2012); Liu et al. } \\
\text { (2013) }\end{array}$} & $\begin{array}{l}\text { Hai River } \\
\text { Basin, China }\end{array}$ & $\begin{array}{l}\text { Mixed (orchard, crops, residential), } \\
\text { mountain valley ('Miyun') }\end{array}$ & $\begin{array}{l}\text { Jan-Jul } 2008 \text { / Jan } \\
\text { 2007-Dec } 2012\end{array}$ & LAS & 2420 & 35.9 & $\begin{array}{l}\text { Similarity scaling assessed, greater deviation } \\
\text { identified at complex site (Miyun). }\end{array}$ \\
\hline & & $\begin{array}{l}\text { Mixed agriculture (maize/winter } \\
\text { wheat, cotton) ('Guantao') }\end{array}$ & $\begin{array}{l}\text { Jan-Jul } 2008 \text { / Jan } \\
\text { 2008-Dec } 2009\end{array}$ & LAS & 2760 & 15.6 & \\
\hline & & $\begin{array}{l}\text { Suburban farmland (maize/winter } \\
\text { wheat, vegetables) ('Daxing') }\end{array}$ & Jun 2006-Dec 2012 & LAS & 2480 & 27.0 & \\
\hline Liu et al. (2011) & $\begin{array}{l}\text { Heihe River } \\
\text { Basin, China }\end{array}$ & Alpine meadow (grass), relatively flat & $\begin{array}{l}11 \text { Mar-31 Oct } \\
\text { 2008; } 01 \text { Jan } 2009- \\
\text { 30 Jun } 2009\end{array}$ & LAS & 2390 & 9.5 & $\begin{array}{l}\text { Similarity scaling assessed. } \\
\text { Heterogeneity quantified using remote } \\
\text { sensing data. }\end{array}$ \\
\hline Brunsell et al. (2011) & $\begin{array}{l}\text { Konza prairie, } \\
\text { Kansas }\end{array}$ & $\begin{array}{l}\text { Upland (dense vegetation) and } \\
\text { lowland (less dense vegetation) tall- } \\
\text { grass prairie }\end{array}$ & 17 Jul-07 Sep 2007 & LAS & 990 & $\approx 8$ & $\begin{array}{l}\text { Comparison of } Q_{H_{-} s c} \text { and } Q_{H_{-} E C} \text {. } \\
\text { LAS used to validate MODIS-derived } Q_{H} \text {. }\end{array}$ \\
\hline $\begin{array}{l}\text { Samain et al. (2011); } \\
\text { Samain et al. (2012a); } \\
\text { Samain et al. (2012b) }\end{array}$ & $\begin{array}{l}\text { Bellebeek } \\
\text { catchment, } \\
\text { Belgium }\end{array}$ & $\begin{array}{l}\text { Mixed land use (agriculture, pasture, } \\
\text { urban, forest, water), variable } \\
\text { topography }\end{array}$ & $\begin{array}{l}21 \text { Feb } 2008-28 \text { Aug } \\
2009\end{array}$ & XLAS & 9500 & 68 & $\begin{array}{l}Q_{H} \text { validated against calibrated energy balance } \\
\text { model (TOPLATS). } \\
Q_{E} \text { estimated using energy balance and } \\
\text { compared with remote sensing algorithm } \\
\text { ETLook. } \\
\text { Consideration of stable conditions and } \\
\text { algorithms for detecting the change in sign of } \\
Q_{H} .\end{array}$ \\
\hline Braam et al. (2012) & $\begin{array}{l}\text { Cabauw, The } \\
\text { Netherlands }\end{array}$ & $\begin{array}{l}\text { Grassland with scattered rows of } \\
\text { trees, flat }\end{array}$ & $\begin{array}{l}04 \text { May-11 May } \\
2008\end{array}$ & XLAS & 9800 & 59.9 & $\begin{array}{l}\text { Measurement often outside surface layer and } \\
\text { cannot be related to surface flux. }\end{array}$ \\
\hline Evans et al. (2012) & $\begin{array}{l}\text { Sheepdrove, } \\
\text { UK }\end{array}$ & $\begin{array}{l}\text { Mixed agriculture (cereals, grass), } \\
\text { undulating terrain }\end{array}$ & 29 Jul-16 Aug 2004 & LAS & 2430 & 32 & $\begin{array}{l}\text { Excellent agreement between } Q_{H_{-} s c} \text { and } \\
Q_{H_{-} E C_{-} a g g} \text { for maturing crops. } \\
\text { Reasonable agreement for } Q_{E} \text { derived as } \\
\text { energy balance residual. }\end{array}$ \\
\hline Geli et al. (2012) & $\begin{array}{l}\text { Southern } \\
\text { California }\end{array}$ & $\begin{array}{l}\text { Varying vegetation height (tamarisk, } \\
\text { arrowweed, cottonwood, mesquite, } \\
\text { bare soil) and topography }\end{array}$ & Summer 2008 & LAS & $\begin{array}{r}1832 \\
1052 \\
1621\end{array}$ & & $\begin{array}{l}\text { Lidar data used to assess impact of } \\
\text { uncertainties in elevation and vegetation } \\
\text { height. }\end{array}$ \\
\hline
\end{tabular}




\begin{tabular}{|c|c|c|c|c|c|c|c|}
\hline Reference & Location & Site description & Study period & Instrument & $L[\mathrm{~m}]$ & $z_{e f}[\mathrm{~m}]$ & Comments \\
\hline \multirow[t]{2}{*}{ Lothon et al. (2014) } & \multirow{2}{*}{$\begin{array}{l}\text { Lannemezan, } \\
\text { France }\end{array}$} & \multirow{2}{*}{$\begin{array}{l}\text { Heterogeneous vegetation } \\
\text { (grassland, meadow, crops, forest), } \\
\text { plateau }\end{array}$} & 14 Jun-08 Jul 2011 & LAS & 3000 & & \multirow[t]{2}{*}{ Overview of BLLAST campaign. } \\
\hline & & & 14 Jun-08 Jul 2011 & LAS & 4000 & & \\
\hline Lee (2015) & $\begin{array}{l}\text { Muchangpo, } \\
\text { South Korea }\end{array}$ & Coastal (path along beach) & 22-23 Nov 2013 & LAS & 1000 & 18.5 & Tides generate $\pm 2 \mathrm{~m}$ change in $z e f$. \\
\hline $\begin{array}{l}\text { Beyrich et al. (2002b); } \\
\text { Lüdi et al. (2005); } \\
\text { Beyrich et al. (2006); } \\
\text { Meijninger et al. } \\
\text { (2006); Beyrich et al. } \\
\text { (2012); Braam et al. } \\
\text { (2016) }\end{array}$ & $\begin{array}{l}\text { LITFASS } \\
\text { Region, } \\
\text { Germany }\end{array}$ & $\begin{array}{l}\text { Heterogeneous vegetation (crops, } \\
\text { grassland, forest, water), moderate } \\
\text { topography }\end{array}$ & $\begin{array}{l}\text { Campaigns in 1998, } \\
2003,2009 ; \\
\text { long-term LAS } \\
\text { operation > } 10 \text { years }\end{array}$ & $\begin{array}{l}\mathrm{LAS}+\mathrm{MWS} \\
(94 \mathrm{GHz})\end{array}$ & 4900 & 43 & $\begin{array}{l}\text { LITFASS campaigns. } \\
\text { Comparisons between LASs, SLSs, EC, } \\
\text { unmanned aerial vehicle, large-eddy } \\
\text { simulations and mesoscale models. } \\
\text { Detailed analysis of } Q_{H}, Q_{E}, C_{T}^{2}, C_{q}{ }^{2} \text {. } \\
\text { First demonstration of bichromatic method to } \\
\text { derive } r_{T q} \text {. }\end{array}$ \\
\hline Rotach et al. (2016) & $\begin{array}{l}\text { Inn Valley, } \\
\text { Austria }\end{array}$ & $\begin{array}{l}\text { U-shaped alpine valley, mixed } \\
\text { agriculture and villages }\end{array}$ & $\begin{array}{l}\text { Example days: } 30 \\
\text { Aug and } 11 \text { Sep } \\
2013\end{array}$ & LAS & 1850 & $\approx 60$ & $\begin{array}{l}\text { LAS path across mountain valley. } \\
Q_{H_{-} s c} \text { compared with } Q_{H_{-} E C} \text { at three heights to } \\
\text { investigate structure of surface layer. }\end{array}$ \\
\hline \multicolumn{8}{|c|}{ Crosswind speed } \\
\hline Poggio et al. (2000) & $\begin{array}{l}\text { Mesolcina } \\
\text { Valley, } \\
\text { Switzerland }\end{array}$ & $\begin{array}{l}\text { Mountain valley; paths across and } \\
\text { parallel to valley }\end{array}$ & Summer 1996 & $5 \times$ LAS & $\begin{array}{l}900- \\
2700\end{array}$ & $\begin{array}{r}\approx 60-600 \\
\text { agl }\end{array}$ & $\begin{array}{l}\text { Heights represent distance to ground near } \\
\text { path centre. } \\
\text { Comparison of six methods to derive } \\
\text { crosswind. } \\
\text { Impact of variable crosswind analysed. }\end{array}$ \\
\hline Furger et al. (2001) & Rhine Valley, & Mountain valley; paths across valley & 20-24 Oct 1999 & LAS & 6500 & $\approx 500 \mathrm{agl}$ & Heights represent distance to ground near \\
\hline & Switzerland & & 20-24 Oct 1999 & LAS & 6200 & $\approx 500 \mathrm{agl}$ & $\begin{array}{l}\text { path centre. } \\
\text { Horizontal and vertical wind derived during } \\
\text { foehn. }\end{array}$ \\
\hline Wood et al. (2013b) & London, UK & Dense urban; path crosses river & 18 Feb-17 May 2011 & LAS & 808 & $\approx 40-50 \mathrm{agl}$ & $\begin{array}{l}\text { Comparison of sonic, lidar and scintillometer } \\
\text { wind measurements. } \\
\text { Channelling over River Thames. Lidar provides } \\
\text { profile, whereas scintillometer is path- } \\
\text { averaged value. }\end{array}$ \\
\hline $\begin{array}{l}\text { van Dinther et al. } \\
\text { (2015b) }\end{array}$ & $\begin{array}{l}\text { Helsinki, } \\
\text { Finland }\end{array}$ & Urban & 1-15 Oct 2013 & LAS & 4190 & 33.6 & $\begin{array}{l}\text { Lidar used to evaluate scintillometer } \\
\text { crosswind retrieval. } \\
\text { Updates to look-up-table method to improve } \\
\text { performance when crosswind variable. }\end{array}$ \\
\hline $\begin{array}{l}\text { van Dinther et al. } \\
\text { (2015a) }\end{array}$ & $\begin{array}{l}\text { Schiphol } \\
\text { airport, The } \\
\text { Netherlands }\end{array}$ & Airport; path 150 m from runway & 26 Jul-29 Aug 2013 & LAS & 1060 & 3.2 & $\begin{array}{l}\text { Scintillometer used to estimate crosswind, } \\
\text { visibility and detect wake vortices from } \\
\text { aircraft wings. }\end{array}$ \\
\hline
\end{tabular}




\begin{tabular}{|c|c|c|c|c|c|c|c|}
\hline Reference & Location & Site description & Study period & Instrument & $L[\mathrm{~m}]$ & $z_{e f}[\mathrm{~m}]$ & Comments \\
\hline \multicolumn{8}{|c|}{ Rainfall } \\
\hline Leijnse et al. (2007b) & $\begin{array}{l}\text { Wageningen, } \\
\text { The } \\
\text { Netherlands }\end{array}$ & Mixed land cover; slightly sloping & 28 May-23 Jul 1999 & $\begin{array}{l}\text { MWS }(27 \\
\text { GHz) }\end{array}$ & 4890 & & $\begin{array}{l}\text { Comparison with seven tipping bucket gauges } \\
\text { along path. } \\
Q_{E} \text { retrieval not possible due to trees } \\
\text { reflecting the beam. }\end{array}$ \\
\hline Uijlenhoet et al. (2011) & & See $G$ & et al. (2009) & & & & $\begin{array}{l}5 \text {-min scintillometer rain estimates within } 20 \% \\
\text { of gauge values. }\end{array}$ \\
\hline \multicolumn{8}{|c|}{ Visibility and pollution } \\
\hline $\begin{array}{l}\text { Yuan et al. (2015); } \\
\text { Yuan et al. (2016) }\end{array}$ & Hefei, China & Urban, heavy traffic & $\begin{array}{l}\text { 15-16 Jan 2014; } \\
\text { 20-29 Dec 2014 }\end{array}$ & $\begin{array}{l}\text { LAS }(0.62 \\
\mu \mathrm{m})\end{array}$ & 960 & 18.0 & $\begin{array}{l}\text { Imaginary part of refractive index fluctuations } \\
\text { related to visibility and aerosol mass flux. } \\
\text { No direct evaluation. }\end{array}$ \\
\hline
\end{tabular}

Table 2: Summary of scintillometer studies relevant to urban and complex environments. Unless otherwise stated, the 'zef' column contains the effective height or ( $z m-z d)$ depending on the

information provided in the reference. Where multiple publications use the same dataset, the study period may differ for the individual publications. For a list of studies including non-

complex environments, see Table 1.2 of Meijninger (2003) for long-path and Table 1 of Odhiambo and Savage (2009) for short-path studies. 


\section{References}

Andreas EL 1988 Estimating $\mathrm{C}_{\mathrm{n}}{ }^{2}$ over snow and sea ice from meteorological data Journal of the Optical Society of America 5 481-495

Andreas EL 1989 Two-wavelength method of measuring path-averaged turbulent surface heat fluxes J. Atmos. Ocean. Technol. 6 280-292

Andreas EL, Hill RJ, Gosz JR, Moore DI, Otto WD and Sarma AD 1998 Statistics of surface-layer turbulence over terrain with metre-scale heterogeneity Bound.-Layer Meteor. 86 379-408

Asanuma J and lemoto K 2007 Measurements of regional sensible heat flux over Mongolian grassland using large aperture scintillometer Journal of Hydrology 333 58-67 doi: 10.1016/j.jhydrol.2006.07.031

Aubinet M, Vesala T and Papale D 2012 Eddy covariance: A practical guide to measurement and data analysis (The Netherlands: Springer Atmospheric Sciences) 438 pp.

Bai J, Liu S and Mao D 2009 Area-averaged evapotranspiration fluxes measured from large aperture scintillometer in the Hai river basin, Proceedings of International Symposium of Hai Basin Integrated Water and Environment Management, Beijing, China

Baldocchi D et al. 2001 FLUXNET: A new tool to study the temporal and spatial variability of ecosystem-scale carbon dioxide, water vapor, and energy flux densities Bull. Amer. Meteorol. Soc. 82 2415-2434 doi: 10.1175/1520-0477(2001)082<2415:FANTTS>2.3.CO;2

Bange J, Beyrich F and Engelbart MDA 2002 Airborne measurements of turbulent fluxes during LITFASS-98: Comparison with ground measurements and remote sensing in a case study Theoretical and Applied Climatology 73 35-51 doi: 10.1007/s00704-002-0692-6

Beyrich F et al. 2012 Towards a validation of scintillometer measurements: The LITFASS-2009 experiment Bound.-Layer Meteor. 144 83-112 doi: 10.1007/s10546-012-9715-8

Beyrich F, De Bruin HAR, Meijninger WML, Schipper JW and Lohse H 2002a Results from one-year continuous operation of a large aperture scintillometer over a heterogeneous land surface Bound.-Layer Meteor. 105 85-97

Beyrich F, Kouznetsov RD, Leps JP, Lüdi A, Meijninger WML and Weisensee U 2005 Structure parameters for temperature and humidity from simultaneous eddy-covariance and scintillometer measurements Meteorol. Z. 14 641-649 doi: 10.1127/0941-2948/2005/0064

Beyrich F et al. 2006 Area-averaged surface fluxes over the LITFASS region based on eddy-covariance measurements Bound.-Layer Meteor. 121 33-65 doi: 10.1007/s10546-006-9052-x

Beyrich F and Mengelkamp HT 2006 Evaporation over a heterogeneous land surface: EVA_GRIPS and the LITFASS-2003 experiment - an overview Bound.-Layer Meteor. 121 5-32 doi: 10.1007/s10546-006-9079-z

Beyrich F, Richter SH, Weisensee U, Herzog HJ, De Bruin HAR and Meijninger WML 2002b Fluxes over a heterogeneous land surface: Results and perspectives of the LITFASS program 15th Symposium on Boundary Layers and Turbulence 653-654

Braam M, Beyrich F, Bange J, Platis A, Martin S, Maronga B and Moene AF 2016 On the discrepancy in simultaneous observations of the structure parameter of temperature using scintillometers and unmanned aircraft Bound.-Layer Meteor. 158 257-283 doi: 10.1007/s10546-015-0086-9

Braam M, Bosveld F and Moene A 2012 On Monin-Obukhov scaling in and above the atmospheric surface layer: The complexities of elevated scintillometer measurements Bound.-Layer Meteor. 144 157-177 doi: 10.1007/s10546-012-9716-7

Braam M, Moene A, Beyrich F and Holtslag AM 2014a Similarity relations for $C_{T}{ }^{2}$ in the unstable atmospheric surface layer: Dependence on regression approach, observation height and stability range Bound.-Layer Meteor. 153 63-87 doi: 10.1007/s10546-014-9938-y

Braam M, Moene AF and Beyrich F 2014b Variability of the structure parameters of temperature and humidity observed in the atmospheric surface layer under unstable conditions Bound.-Layer Meteor. 150 399-422 doi: 10.1007/s10546-013-9882-2 
Brunsell N, Ham J and Arnold K 2011 Validating remotely sensed land surface fluxes in heterogeneous terrain with large aperture scintillometry International journal of remote sensing 32 6295-6314

Cammalleri C, Agnese C, Ciraolo G, Minacapilli M, Provenzano G and Rallo G 2010 Actual evapotranspiration assessment by means of a coupled energy/hydrologic balance model: Validation over an olive grove by means of scintillometry and measurements of soil water contents Journal of Hydrology 392 70-82 doi: 10.1016/j.jhydrol.2010.07.046

Chehbouni A et al. 1999 Estimation of area-average sensible heat flux using a large-aperture scintillometer during the semi-arid land-surface-atmosphere (SALSA) experiment Water Resour. Res. 35 2505-2511

Chehbouni $A$ et al. 2000 Estimation of heat and momentum fluxes over complex terrain using a large aperture scintillometer Agric. For. Meteorol. 105 215-226

Chen J, Wang J and Horiguchi M 1993 An independent method to determine the surface roughness length Chinese J. Atmos. Sci 17 21-26

Churnside JH, Lataitis RJ and Lawrence RS 1988 Localized measurements of refractive turbulence using spatial-filtering of scintillations Applied Optics 27 2199-2213

Clifford SF, Ochs GR and Lawrence RS 1974 Saturation of optical scintillation by strong turbulence Journal of the Optical Society of America 64 148-154

Crawford B, Grimmond CSB, Ward HC, Morrison W and Kotthaus S 2017 Spatial and temporal patterns of surface-atmosphere energy exchange in a dense urban environment using scintillometry Q. J. R. Meteorol. Soc. doi: 10.1002/qj.2967

De Bruin H 2002 Introduction: Renaissance of scintillometry Bound.-Layer Meteor. 105 1-4 doi: 10.1023/a:1019628124829

De Bruin HAR, Hartogensis OK, Allen RG and Kramer JWJL 2005 Regional advection perturbations in an irrigated desert (RAPID) experiment Theoretical and Applied Climatology 80 143-152 doi: 10.1007/s00704-004-0096-x

De Bruin HAR, Kohsiek W and Van den Hurk BJJM 1993 A verification of some methods to determine the fluxes of momentum, sensible heat, and water-vapour using standard-deviation and structure parameter of scalar meteorological quantities Bound.-Layer Meteor. 63 231-257

De Bruin HAR, Meijninger WML, Smedman A-S and Magnusson M 2002 Displaced-beam small aperture scintillometer test. Part I: The WINTEX data-set Bound.-Layer Meteor. 105 129-148 doi: 10.1023/a:1019639631711

De Bruin HAR, Van den Hurk BJJM and Kohsiek W 1995 The scintillation method tested over a dry vineyard area Bound.-Layer Meteor. 76 25-40

De Bruin HAR, Van den Hurk BJJM and Kroon LM 1999 On the temperature-humidity correlation and similarity Bound.-Layer Meteor. 93 453-468

Evans JG, 2009 Long-path scintillometry over complex terrain to determine areal-averaged sensible and latent heat fluxes PhD Thesis University of Reading, Reading, UK $181 \mathrm{pp}$

Evans JG and De Bruin HAR 2011 The effective height of a two-wavelength scintillometer system Bound-Layer Meteor. 141 165-177 doi: 10.1007/s10546-011-9634-0

Evans JG, McNeil DD, Finch JW, Murray T, Harding RJ, Ward HC and Verhoef A 2012 Determination of turbulent heat fluxes using a large aperture scintillometer over undulating mixed agricultural terrain Agric. For. Meteorol. 166-167 221-233

Ezzahar J, Chehbouni A, Er-Raki S and Hanich L 2009a Combining a large aperture scintillometer and estimates of available energy to derive evapotranspiration over several agricultural fields in a semi-arid region Plant Biosystems 143 209-221 doi: 10.1080/11263500802710036

Ezzahar J et al. 2009b Combining scintillometer measurements and an aggregation scheme to estimate area-averaged latent heat flux during the AMMA experiment Journal of Hydrology 375 217-226 doi: 10.1016/j.jhydrol.2009.01.010

Ezzahar J, Chehbouni A and Hoedjes JCB 2007a On the application of scintillometry over heterogeneous grids Journal of Hydrology 334 493-501 doi: 10.1016/j.jhydrol.2006.10.027 
Ezzahar J, Chehbouni A, Hoedjes JCB, Er-Raki S, Chehbouni A, Boulet G, Bonnefond JM and De Bruin HAR 2007b The use of the scintillation technique for monitoring seasonal water consumption of olive orchards in a semi-arid region Agric. Water Manage. 89 173-184 doi: 10.1016/j.agwat.2006.12.015

Finnigan J 2008 An introduction to flux measurements in difficult conditions Ecol. Appl. 18 1340-1350 doi: 10.1890/07-2105.1

Foken T 2008 The energy balance closure problem: An overview Ecol. Appl. 18 1351-1367

Frehlich R 1992 Laser scintillation measurements of the temperature spectrum in the atmospheric surface-layer Journal of the Atmospheric Sciences 49 1494-1509

Furger M, Drobinski P, Prévôt AH, Weber RO, Graber WK and Neininger B 2001 Comparison of horizontal and vertical scintillometer crosswinds during strong foehn with lidar and aircraft measurements J. Atmos. Ocean. Technol. 18 1975-1988 doi: 10.1175/15200426(2001)018<1975:COHAVS>2.0.CO;2

Galvez JM, 2011 Integrated role of the urban canopy on turbulent transfer with the roughness sublayer from observations PhD Thesis The University of Oklahoma

Garratt JR 1978 Transfer characteristics for a heterogeneous surface of large aerodynamic roughness Q. J. R. Meteorol. Soc. 104 491-502 doi: 10.1002/qj.49710444019

Garratt JR 1992 The atmospheric boundary layer (Cambridge, UK: Cambridge University Press) 316 $\mathrm{pp}$.

Geli HME, Neale CMU, Watts D, Osterberg J, De Bruin HAR, Kohsiek W, Pack RT and Hipps LE 2012 Scintillometer-based estimates of sensible heat flux using lidar-derived surface roughness Journal of Hydrometeorology 13 1317-1331 doi: 10.1175/JHM-D-11-085.1

Göckede M, Markkanen T, Mauder M, Arnold K, Leps J-P and Foken T 2005 Validation of footprint models using natural tracer measurements from a field experiment Agric. For. Meteorol. 135 314-325 doi: 10.1016/j.agrformet.2005.12.008

Green AE and Hayashi Y 1998 Use of the scintillometer technique over a rice paddy Japanese Journal of Agricultural Meteorology 54 225-231

Grimmond CSB, King TS, Roth M and Oke TR 1998 Aerodynamic roughness of urban areas derived from wind observations Bound.-Layer Meteor. 89 1-24

Grimmond CSB and Oke TR 1999 Aerodynamic properties of urban areas derived from analysis of surface form J. Appl. Meteorol. 38 1262-1292

Guyot A, Cohard J-M, Anquetin S, Galle S and Lloyd CR 2009 Combined analysis of energy and water balances to estimate latent heat flux of a sudanian small catchment Journal of Hydrology $375227-240$

Hartogensis OK, 2006 Exploring scintillometry in the stable atmospheric surface layer PhD Thesis Wageningen University $240 \mathrm{pp}$

Hartogensis OK and De Bruin HAR 2005 Monin-Obukhov similarity functions of the structure parameter of temperature and turbulent kinetic energy dissipation rate in the stable boundary layer Bound.-Layer Meteor. 116 253-276 doi: 10.1007/s10546-004-2817-1

Hartogensis OK, De Bruin HAR and Van De Wiel BJH 2002 Displaced-beam small aperture scintillometer test. Part ii: Cases-99 stable boundary-layer experiment Bound.-Layer Meteor. 105 149-176 doi: 10.1023/a:1019620515781

Hartogensis OK, Watts CJ, Rodriguez JC and De Bruin HAR 2003 Derivation of an effective height for scintillometers: La poza experiment in northwest Mexico Journal of Hydrometeorology 4 915-928

Hemakumara HM, Chandrapala L and Moene AF 2003 Evapotranspiration fluxes over mixed vegetation areas measured from large aperture scintillometer Agric. Water Manage. 58 109122 doi: 10.1016/S0378-3774(02)00131-2

Hicks BB 1981 An examination of turbulence statistics in the surface boundary layer Bound.-Layer Meteor. 21 389-402 doi: 10.1007/bf00119281 
Hill RJ 1988 Comparison of scintillation methods for measuring the inner scale of turbulence Applied Optics 27 2187-2193

Hill RJ 1989 Implications of Monin-Obukhov similarity theory for scalar quantities Journal of the Atmospheric Sciences 46 2236-2244

Hill RJ 1992 Review of optical scintillation methods of measuring the refractive-index spectrum, inner scale and surface fluxes Waves Random Media 2 179-201

Hill RJ, Bohlander RA, Clifford SF, McMillan RW, Priestly JT and Schoenfeld WP 1988 Turbulenceinduced millimeter-wave scintillation compared with micrometeorological measurements IEEE Transactions on Geoscience and Remote Sensing 26 330-342

Hill RJ, Clifford SF and Lawrence RS 1980 Refractive-index and absorption fluctuations in the infrared caused by temperature, humidity, and pressure fluctuations J. Opt. Soc. Am. 70 1192-1205

Hill RJ, Ochs GR and Wilson JJ 1992 Measuring surface-layer fluxes of heat and momentum using optical scintillation Bound.-Layer Meteor. 58 391-408 doi: 10.1007/bf00120239

Hoedjes JCB, Chehbouni A, Ezzahar J, Escadafal R and De Bruin HAR 2007 Comparison of large aperture scintillometer and eddy covariance measurements: Can thermal infrared data be used to capture footprint-induced differences? Journal of Hydrometeorology 8 144-159 doi: 10.1175/jhm561.1

Hoedjes JCB, Zuurbier RM and Watts CJ 2002 Large aperture scintillometer used over a homogeneous irrigated area, partly affected by regional advection Bound.-Layer Meteor. 105 99-117

Jacobs C, Elbers J, Brolsma R, Hartogensis O, Moors E, Rodríguez-Carretero Márquez MT and van Hove B 2015 Assessment of evaporative water loss from Dutch cities Building and Environment 83 27-38 doi: 10.1016/j.buildenv.2014.07.005

Jia Z, Liu S, Xu Z, Chen Y and Zhu M 2012 Validation of remotely sensed evapotranspiration over the Hai river basin, China Journal of Geophysical Research: Atmospheres 117 D13113 doi: 10.1029/2011JD017037

Kanda M, Inagaki A, Miyamoto T, Gryschka M and Raasch S 2013 A new aerodynamic parametrization for real urban surfaces Bound.-Layer Meteor. 148 357-377 doi: 10.1007/s10546-013-9818-x

Kanda M, Moriwaki R, Roth M and Oke T 2002 Area-averaged sensible heat flux and a new method to determine zero-plane displacement length over an urban surface using scintillometry Bound.-Layer Meteor. 105 177-193

Kanda M, Takayanagi Y, Yokoyama H and Moriwaki R 1997 Field observation of the heat balance in an urban area Journal of Japan Society of Hydrology and Water Resources 10 329-336 doi: 10.3178/jjshwr.10.329

Katul G, Goltz SM, Hsieh C-I, Cheng Y, Mowry F and Sigmon J 1995 Estimation of surface heat and momentum fluxes using the flux-variance method above uniform and non-uniform terrain Bound.-Layer Meteor. 74 237-260 doi: 10.1007/bf00712120

Katul GG, Finnigan JJ, Poggi D, Leuning R and Belcher SE 2006 The influence of hilly terrain on canopy-atmosphere carbon dioxide exchange Bound.-Layer Meteor. 118 189-216 doi: 10.1007/s10546-005-6436-2

Katul GG, Sempreviva AM and Cava D 2008 The temperature-humidity covariance in the marine surface layer: A one-dimensional analytical model Bound.-Layer Meteor. 126 263-278 doi: 10.1007/s10546-007-9236-z

Kleissl J, Hartogensis O and Gomez J 2010 Test of scintillometer saturation correction methods using field experimental data Bound.-Layer Meteor. 137 493-507 doi: 10.1007/s10546-010-9540-x

Kleissl J, Hong SH and Hendrickx JMH 2009 New Mexico scintillometer network supporting remote sensing and hydrologic and meteorological models Bull. Amer. Meteorol. Soc. 90 207-218 doi: $10.1175 / 2008$ bams 2480.1

Kohsiek W 1982 Measuring $\mathrm{C}_{\mathrm{T}}{ }^{2}, \mathrm{C}_{\mathrm{Q}}{ }^{2}$, and $\mathrm{C}_{\mathrm{TQ}}$ in the unstable surface-layer, and relations to the vertical fluxes of heat and moisture Bound.-Layer Meteor. 24 89-107 
Kohsiek W, Meijninger WML, De Bruin HAR and Beyrich F 2006 Saturation of the large aperture scintillometer Bound.-Layer Meteor. 121 111-126 doi: 10.1007/s10546-005-9031-7

Kooijmans LMJ and Hartogensis OK 2016 Surface-layer similarity functions for dissipation rate and structure parameters of temperature and humidity based on eleven field experiments Bound.-Layer Meteor. 160 501-527 doi: 10.1007/s10546-016-0152-y

Kotthaus S and Grimmond CSB 2014 Energy exchange in a dense urban environment - Part II: Impact of spatial heterogeneity of the surface Urban Climate 10 281-307 doi: 10.1016/j.uclim.2013.10.001

Lagouarde JP, Bonnefond JM, Kerr YH, McAneney KJ and Irvine M 2002 Integrated sensible heat flux measurements of a two-surface composite landscape using scintillometry Bound.-Layer Meteor. 105 5-35 doi: 10.1023/a:1019631428921

Lagouarde JP, Irvine M, Bonnefond JM, Grimmond CSB, Long N, Oke TR, Salmond JA and Offerle B 2006 Monitoring the sensible heat flux over urban areas using large aperture scintillometry: Case study of Marseille city during the ESCOMPTE experiment Bound.-Layer Meteor. 118 449-476 doi: 10.1007/s10546-005-9001-0

Lamaud E and Irvine M 2006 Temperature-humidity dissimilarity and heat-to-water-vapour transport efficiency above and within a pine forest canopy: The role of the Bowen ratio Bound.-Layer Meteor. 120 87-109 doi: 10.1007/s10546-005-9032-6

Lawrence RS, Ochs GR and Clifford SF 1972 Use of scintillations to measure average wind across a light-beam Applied Optics 11 239-243

Leclerc MY and Foken T 2014 Footprints in micrometeorology and ecology (Berlin: Springer).

Lee S-H 2015 Determination of turbulent sensible heat flux over a coastal maritime area using a large aperture scintillometer Bound.-Layer Meteor. 157 309-319 doi: 10.1007/s10546-015-0036-6

Lee S-H, Lee J-H and Kim B-Y 2015 Estimation of turbulent sensible heat and momentum fluxes over a heterogeneous urban area using a large aperture scintillometer Adv. Atmos. Sci. 32 10921105 doi: 10.1007/s00376-015-4236-2

Leijnse $\mathrm{H}$, Uijlenhoet R and Stricker JNM 2007a Hydrometeorological application of a microwave link: 1. Evaporation Water Resour. Res. 43 W04416 doi: 10.1029/2006wr004988

Leijnse $\mathrm{H}$, Uijlenhoet $\mathrm{R}$ and Stricker JNM 2007b Hydrometeorological application of a microwave link: 2. Precipitation Water Resour. Res. 43 W04417 doi: 10.1029/2006wr004989

Leijnse $H$, Uijlenhoet R and Stricker JNM 2008 Microwave link rainfall estimation: Effects of link length and frequency, temporal sampling, power resolution, and wet antenna attenuation Adv. Water Resour. 31 1481-1493

Li D, Bou-Zeid E and De Bruin HAR 2012 Monin-Obukhov similarity functions for the structure parameters of temperature and humidity Bound.-Layer Meteor. 145 45-67 doi: 10.1007/s10546-011-9660-y

Liu SM, Xu ZW, Wang WZ, Jia ZZ, Zhu MJ, Bai J and Wang JM 2011 A comparison of eddy-covariance and large aperture scintillometer measurements with respect to the energy balance closure problem Hydrol. Earth Syst. Sci. 15 1291-1306 doi: 10.5194/hess-15-1291-2011

Liu SM, Xu ZW, Zhu ZL, Jia ZZ and Zhu MJ 2013 Measurements of evapotranspiration from eddycovariance systems and large aperture scintillometers in the Hai river basin, China Journal of Hydrology 487 24-38 doi: 10.1016/j.jhydrol.2013.02.025

Lothon $\mathrm{M}$ et al. 2014 The BLLAST field experiment: Boundary-layer late afternoon and sunset turbulence Atmos. Chem. Phys. 14 10931-10960 doi: 10.5194/acp-14-10931-2014

Lüdi A, Beyrich F and Matzler C 2005 Determination of the turbulent temperature-humidity correlation from scintillometric measurements Bound.-Layer Meteor. 117 525-550 doi: 10.1007/s10546-005-1751-1

Macdonald RW, Griffiths RF and Hall DJ 1998 An improved method for the estimation of surface roughness of obstacle arrays Atmospheric Environment 32 1857-1864 doi: 10.1016/S13522310(97)00403-2 
Maronga B, Hartogensis OK, Raasch S and Beyrich F 2014 The effect of surface heterogeneity on the structure parameters of temperature and specific humidity: A large-eddy simulation case study for the LITFASS-2003 experiment Bound.-Layer Meteor. 153 441-470 doi: 10.1007/s10546-014-9955-x

Maronga B, Moene AF, Dinther D, Raasch S, Bosveld FC and Gioli B 2013 Derivation of structure parameters of temperature and humidity in the convective boundary layer from large-eddy simulations and implications for the interpretation of scintillometer observations Bound.Layer Meteor. 148 1-30 doi: 10.1007/s10546-013-9801-6

Maronga B and Raasch S 2013 Large-eddy simulations of surface heterogeneity effects on the convective boundary layer during the LITFASS-2003 experiment Bound.-Layer Meteor. 146 17-44 doi: 10.1007/s10546-012-9748-z

Marx A, Kunstmann H, Schüttemeyer D and Moene AF 2008 Uncertainty analysis for satellite derived sensible heat fluxes and scintillometer measurements over savannah environment and comparison to mesoscale meteorological simulation results Agric. For. Meteorol. 148 656667 doi: 10.1016/j.agrformet.2007.11.009

Masson V et al. 2008 The canopy and aerosol particles interactions in toulouse urban layer (CAPITOUL) experiment Meteorology and Atmospheric Physics 102 135-157 doi: 10.1007/s00703-008-0289-4

Matzinger N, Andretta M, Gorsel EV, Vogt R, Ohmura A and Rotach MW 2003 Surface radiation budget in an Alpine valley Q. J. R. Meteorol. Soc. 129 877-895 doi: 10.1256/qj.02.44

Mauder M et al. 2007 The energy balance experiment EBEX-2000. Part II: Intercomparison of eddycovariance sensors and post-field data processing methods Bound.-Layer Meteor. 123 29-54 doi: 10.1007/s10546-006-9139-4

McAneney KJ, Green AE and Astill MS 1995 Large-aperture scintillometry: The homogeneous case Agric. For. Meteorol. 76 149-162 doi: 10.1016/0168-1923(95)02227-O

Meijninger WML, 2003 Surface fluxes over natural landscapes using scintillometry PhD Thesis Wageningen University, Wageningen, The Netherlands $170 \mathrm{pp}$

Meijninger WML, Beyrich F, Lüdi A, Kohsiek W and De Bruin HAR 2006 Scintillometer-based turbulent fluxes of sensible and latent heat over a heterogeneous land surface - a contribution to LITFASS-2003 Bound.-Layer Meteor. 121 89-110 doi: 10.1007/s10546-0059022-8

Meijninger WML and De Bruin HAR 2000 The sensible heat fluxes over irrigated areas in western Turkey determined with a large aperture scintillometer Journal of Hydrology 229 42-49

Meijninger WML, Green AE, Hartogensis OK, Kohsiek W, Hoedjes JCB, Zuurbier RM and De Bruin HAR 2002a Determination of area-averaged water vapour fluxes with large aperture and radio wave scintillometers over a heterogeneous surface - Flevoland field experiment Bound.Layer Meteor. 105 63-83

Meijninger WML, Hartogensis OK, Kohsiek W, Hoedjes JCB, Zuurbier RM and De Bruin HAR 2002b Determination of area-averaged sensible heat fluxes with a large aperture scintillometer over a heterogeneous surface - Flevoland field experiment Bound.-Layer Meteor. 105 37-62

Mestayer P et al. 2011 The FluxSAP 2010 hydroclimatological experimental campaign over an heterogeneous urban area, 11th EMS Annual Meeting, Berlin, Germany

Min W, Chen Z, Sun L, Gao W, Luo X, Yang T, Pu J, Huang G and Yang X 2004 A scheme for pixel-scale aerodynamic surface temperature over hilly land Adv. Atmos. Sci. 21 125-131 doi: 10.1007/bf02915686

Moene A and Schüttemeyer D 2008 The effect of surface heterogeneity on the temperaturehumidity correlation and the relative transport efficiency Bound.-Layer Meteor. 129 99-113 doi: 10.1007/s10546-008-9312-z

Moene AF 2003 Effects of water vapour on the structure parameter of the refractive index for nearinfrared radiation Bound.-Layer Meteor. 107 635-653 
Moene AF, Beyrich F and Hartogensis OK 2009 Developments in scintillometry Bull. Amer. Meteorol. Soc. 90 694-698 doi: 10.1175/2008bams2672.1

Moene AF, Meijninger WML, Hartogensis OK, Kohsiek W and De Bruin HAR 2004 A review of the relationships describing the signal of a large aperture scintillometer, internal report 2004/2 Meteorology and Air Quality Group, Wageningen University, Wageningen, The Netherlands

Monin AS and Yaglom AM 1971 Statistical fluid mechanics: Mechanics of turbulence (Cambridge, Massachusetts: The MIT Press) $782 \mathrm{pp}$.

Nadeau DF, Brutsaert W, Parlange MB, Bou-Zeid E, Barrenetxea G, Couach O, Boldi M-O, Selker JS and Vetterli M 2009 Estimation of urban sensible heat flux using a dense wireless network of observations Environmental Fluid Mechanics 9 635-653 doi: 10.1007/s10652-009-9150-7

Nakaya K, Suzuki C, Kobayashi T, Ikeda H and Yasuike S 2006 Application of a displaced-beam small aperture scintillometer to a deciduous forest under unstable atmospheric conditions Agric. For. Meteorol. 136 45-55 doi: 10.1016/j.agrformet.2005.12.009

Nakaya K, Suzuki C, Kobayashi T, Ikeda H and Yasuike S 2007 Spatial averaging effect on local flux measurement using a displaced-beam small aperture scintillometer above the forest canopy Agric. For. Meteorol. 145 97-109 doi: 10.1016/j.agrformet.2007.04.005

Nieveen JP, Green AE and Kohsiek W 1998 Using a large-aperture scintillometer to measure absorption and refractive index fluctuations Bound.-Layer Meteor. 87 101-116

Nordbo A, Järvi L, Haapanala S, Moilanen J and Vesala T 2013 Intra-city variation in urban morphology and turbulence structure in Helsinki, Finland Bound.-Layer Meteor. 146 469-496 doi: 10.1007/s10546-012-9773-y

Odhiambo GO and Savage MJ 2009 Surface layer scintillometry for estimating the sensible heat flux component of the surface energy balance South African Journal of Science 105 208-216 doi: $10.4102 /$ sajs.v105i5/6.92

Offerle B, Grimmond CSB and Fortuniak K 2005 Heat storage and anthropogenic heat flux in relation to the energy balance of a central European city centre International Journal of Climatology 25 1405-1419 doi: 10.1002/joc.1198

Oke TR 1987 Boundary layer climates (London, UK: Routledge, Taylor and Francis Group) 435 pp.

Panofsky HA and Dutton JA 1984 Atmospheric turbulence: Models and methods for engineering aplications Atmospheric turbulence: Models and methods for engineering applications (New York: John Wiley \& Sons), pp. 389.

Pasquill F 1974 Atmospheric diffusion (New York: Wiley) 429 pp.

Pauscher L, 2010 Scintillometer measurements above the urban area of London University of Bayreuth, Bayreuth, Germany 104 pp

Poggio LP, Furger M, Prevot ASH, Graber WK and Andreas EL 2000 Scintillometer wind measurements over complex terrain J. Atmos. Ocean. Technol. 17 17-26

Roberts SM, Oke TR, Grimmond CSB and Voogt JA 2006 Comparison of four methods to estimate urban heat storage Journal of Applied Meteorology and Climatology 45 1766-1781 doi: 10.1175/jam2432.1

Rotach MW 1993 Turbulence close to a rough urban surface part II: Variances and gradients Bound.Layer Meteor. 66 75-92 doi: 10.1007/bf00705460

Rotach MW 1994 Determination of the zero plane displacement in an urban environment Bound.Layer Meteor. 67 187-193 doi: 10.1007/bf00705513

Rotach MW, Andretta M, Calanca P, Weigel AP and Weiss A 2008 Boundary layer characteristics and turbulent exchange mechanisms in highly complex terrain Acta Geophysica 56 194-219 doi: 10.2478/s11600-007-0043-1

Rotach MW et al. 2004 Turbulence structure and exchange processes in an Alpine valley: The Riviera project Bull. Amer. Meteorol. Soc. 85 1367-1385 doi: 10.1175/BAMS-85-9-1367

Rotach MW, Stiperski I, Fuhrer O, Goger B, Gohm A, Obleitner F, Rau G, Sfyri E and Vergeiner J 2016 Investigating exchange processes over complex topography: The Innsbruck-box (i-Box) Bull. 
Amer. Meteorol. Soc. (early online) doi: 10.1175/BAMS-D-1115-00246.00241 doi: 10.1175/BAMS-D-15-00246.1

Rotach MW et al. 2005 BUBBLE - an urban boundary layer meteorology project Theoretical and Applied Climatology 81 231-261 doi: 10.1007/s00704-004-0117-9

Rotach MW and Zardi D 2007 On the boundary-layer structure over highly complex terrain: Key findings from MAP Q. J. R. Meteorol. Soc. 133 937-948 doi: 10.1002/qj.71

Roth M 1993 Turbulent transfer relationships over an urban surface. li: Integral statistics $Q$. J. $R$. Meteorol. Soc. 119 1105-1120 doi: 10.1002/qj.49711951312

Roth M, Salmond JA and Satyanarayana ANV 2006 Methodological considerations regarding the measurement of turbulent fluxes in the urban roughness sublayer: The role of scintillometery Bound.-Layer Meteor. 121 351-375 doi: 10.1007/s10546-006-9074-4

Sailor DJ 2011 A review of methods for estimating anthropogenic heat and moisture emissions in the urban environment International Journal of Climatology 31 189-199 doi: 10.1002/joc.2106

Salmond JA, Roth M, Oke TR, Christen A and Voogt JA 2012 Can surface-cover tiles be summed to give neighborhood fluxes in cities? Journal of Applied Meteorology and Climatology 51 133149 doi: doi:10.1175/JAMC-D-11-078.1

Samain B, Defloor W and Pauwels VRN 2012a Continuous time series of catchment-averaged sensible heat flux from a large aperture scintillometer: Efficient estimation of stability conditions and importance of fluxes under stable conditions Journal of Hydrometeorology 13 423-442 doi: 10.1175/jhm-d-11-030.1

Samain B, Ferket BVA, Defloor W and Pauwels VRN 2011 Estimation of catchment averaged sensible heat fluxes using a large aperture scintillometer Water Resour. Res. 47 W05536 doi: 10.1029/2009wr009032

Samain B, Simons GWH, Voogt MP, Defloor W, Bink N-J and Pauwels VRN 2012b Consistency between hydrological model, large aperture scintillometer and remote sensing based evapotranspiration estimates for a heterogeneous catchment Hydrology and Earth System Sciences 16 2095-2107 doi: 10.5194/hess-16-2095-2012

Savage MJ 2009 Estimation of evaporation using a dual-beam surface layer scintillometer and component energy balance measurements Agric. For. Meteorol. 149 501-517 doi: 10.1016/j.agrformet.2008.09.012

Schmid HP, Cleugh HA, Grimmond CSB and Oke TR 1991 Spatial variability of energy fluxes in suburban terrain Bound.-Layer Meteor. 54 249-276 doi: 10.1007/bf00183956

Schüttemeyer D, Moene AF, Holtslag AAM, De Bruin HAR and Giesen Nv 2006 Surface fluxes and characteristics of drying semi-arid terrain in West Africa Bound.-Layer Meteor. 118 583-612 doi: 10.1007/s10546-005-9028-2

Schüttemeyer D, Schillings C, Moene A and De Bruin H 2007 Satellite-based actual evapotranspiration over drying semiarid terrain in West Africa Journal of Applied Meteorology and Climatology 46 97-111 doi: doi:10.1175/JAM2444.1

Solignac PA, Brut A, Selves JL, Béteille JP and Gastellu-Etchegorry JP 2012 Attenuating the absorption contribution on $\mathrm{C}_{\mathrm{n}}{ }^{2}$ estimates with a large-aperture scintillometer Bound.-Layer Meteor. 143 261-283 doi: 10.1007/s10546-011-9692-3

Spronken-Smith RA, Oke TR and Lowry WP 2000 Advection and the surface energy balance across an irrigated urban park International Journal of Climatology 20 1033-1047

Stiperski I and Rotach MW 2016 On the measurement of turbulence over complex mountainous terrain Bound.-Layer Meteor. 159 97-121 doi: 10.1007/s10546-015-0103-z

Stull RB 1988 An introduction to boundary layer meteorology (Dordrecht, The Netherlands: Kluwer Academic Publishers) $666 \mathrm{pp}$.

Sugawara H, Inagaki A, Roth M and Kanda M 2016 Evaluation of scintillometery measurements of fluxes of momentum and sensible heat in the roughness sublayer Theoretical and Applied Climatology 126 673-681 doi: 10.1007/s00704-015-1556-1 
Thiermann V and GrassI H 1992 The measurement of turbulent surface-layer fluxes by use of bichromatic scintillation Bound.-Layer Meteor. 58 367-389

Timmermans WJ, Su Z and Olioso A 2009 Footprint issues in scintillometry over heterogeneous landscapes Hydrol. Earth Syst. Sci. 13 2179-2190 doi: 10.5194/hess-13-2179-2009

Twine TE, Kustas WP, Norman JM, Cook DR, Houser PR, Meyers TP, Prueger JH, Starks PJ and Wesely ML 2000 Correcting eddy-covariance flux underestimates over a grassland Agric. For. Meteorol. 103 279-300 doi: 10.1016/S0168-1923(00)00123-4

Uijlenhoet R, Cohard J-M and Gosset M 2011 Path-average rainfall estimation from optical extinction measurements using a large-aperture scintillometer Journal of Hydrometeorology 12 955972 doi: doi:10.1175/2011JHM1350.1

Upton GJG, Holt AR, Cummings RJ, Rahimi AR and Goddard JWF 2005 Microwave links: The future for urban rainfall measurement? Atmospheric Research 77 300-312 doi: 10.1016/j.atmosres.2004.10.009

van Dinther D and Hartogensis OK 2014 Using the time-lag correlation function of dual-aperture scintillometer measurements to obtain the crosswind J. Atmos. Ocean. Technol. 31 62-78 doi: doi:10.1175/JTECH-D-13-00118.1

van Dinther D, Hartogensis OK and Holtslag AAM 2015a Runway wake vortex, crosswind, and visibility detection with a scintillometer at schiphol airport Bound.-Layer Meteor. 157 481499 doi: 10.1007/s10546-015-0068-y

van Dinther D, Wood CR, Hartogensis OK, Nordbo A and O'Connor EJ 2015b Observing crosswind over urban terrain using scintillometer and doppler lidar Atmos. Meas. Tech. 8 1901-1911 doi: 10.5194/amt-8-1901-2015

van Dinther DI, Hartogensis OK and Moene AF 2013 Crosswinds from a single-aperture scintillometer using spectral techniques J. Atmos. Ocean. Technol. 30 3-21 doi: 10.1175/jtech-d-12-00069.1

Van Kesteren B, Beyrich F, Hartogensis KO and Braam M 2015 Long-term evaluation of the Scintec boundary-layer scintillometer and the Wageningen large-aperture scintillometer: Implications for scintillometer users Bound.-Layer Meteor. 156 303-323 doi: 10.1007/s10546-015-0023-y

Van Kesteren B, Hartogensis OK, van Dinther D, Moene AF and De Bruin HAR 2012 Measuring H2O and $\mathrm{CO} 2$ fluxes at field scales with scintillometry: Part I - introduction and validation of four methods Agric. For. Meteorol. 178-179 75-87 doi: 10.1016/j.agrformet.2012.09.013

Van Kesteren B, Hartogensis OK, van Dinther D, Moene AF, De Bruin HAR and Holtslag AAM 2013 Measuring $\mathrm{H} 2 \mathrm{O}$ and $\mathrm{CO} 2$ fluxes at field scales with scintillometry: Part II - validation and application of 1-min flux estimates Agric. For. Meteorol. 178-179 88-105 doi: 10.1016/j.agrformet.2013.01.010

Wang TI, Ochs GR and Clifford SF 1978 A saturation-resistant optical scintillometer to measure $C_{n}^{2} J$. Opt. Soc. Am. 68 334-338

Wang TI, Ochs GR and Lawrence RS 1981 Wind measurements by the temporal cross-correlation of the optical scintillations Applied Optics 20 4073-4081

Ward HC, Evans JG and Grimmond CSB 2011 Effects of non-uniform crosswind fields on scintillometry measurements Bound.-Layer Meteor. 141 143-163 doi: 10.1007/s10546-0119626-0

Ward HC, Evans JG and Grimmond CSB 2014 Multi-scale sensible heat fluxes in the urban environment from large aperture scintillometry and eddy covariance Boundary Layer Meteorology 152 65-89 doi: 10.1007/s10546-014-9916-4

Ward HC, Evans JG and Grimmond CSB 2015a Infrared and millimetre-wave scintillometry in the suburban environment - Part 2: Large-area sensible and latent heat fluxes Atmos. Meas. Tech. 8 1407-1424 doi: 10.5194/amt-8-1407-2015

Ward HC, Evans JG, Grimmond CSB and Bradford J 2015b Infrared and millimetre-wave scintillometry in the suburban environment - Part 1: Structure parameters Atmos. Meas. Tech. 8 1385-1405 doi: 10.5194/amt-8-1385-2015 
Ward HC, Evans JG, Hartogensis OK, Moene AF, De Bruin HAR and Grimmond CSB 2013 A critical revision of the estimation of the latent heat flux from two-wavelength scintillometry $Q$. J. $R$. Meteorol. Soc. 139 1912-1922 doi: 10.1002/qj.2076

Weiss Al, 2002 Determination of thermal stratification and turbulence of the atmospheric surface layer over various types of terrain by optical scintillometry PhD Thesis University of Hamburg, Germany $158 \mathrm{pp}$

Weiss Al, Hennes M and Rotach MW 2001 Derivation of refractive index and temperature gradients from optical scintillometry to correct atmospherically induced errors for highly precise geodetic measurements Surv Geophys 22 589-596 doi: 10.1023/a:1015644923182

Wesely ML 1976 Combined effect of temperature and humidity fluctuations on refractive-index J. Appl. Meteorol. 15 43-49

Whiteman CD, Allwine KJ, Fritschen LJ, Orgill MM and Simpson JR 1989 Deep valley radiation and surface energy budget microclimates. Part I: Radiation J. Appl. Meteorol. 28 414-426 doi: doi:10.1175/1520-0450(1989)028<0414:DVRASE>2.0.CO;2

Wieringa J 1993 Representative roughness parameters for homogeneous terrain Bound.-Layer Meteor. 63 323-363 doi: 10.1007/bf00705357

Wilson K et al. 2002 Energy balance closure at FLUXNET sites Agric. For. Meteorol. 113 223-243

Wood CR, Kouznetsov RD, Gierens R, Nordbo A, Järvi L, Kallistratova MA and Kukkonen J 2013a On the temperature structure parameter and sensible heat flux over Helsinki from sonic anemometry and scintillometry J. Atmos. Ocean. Technol. 30 1604-1615 doi: 10.1175/JTECHD-12-00209.1

Wood CR, Pauscher L, Ward HC, Kotthaus S, Barlow JF, Gouvea M, Lane SE and Grimmond CSB 2013b Wind observations above an urban river using a new lidar technique, scintillometry and anemometry Science of The Total Environment 442 527-533 doi: 10.1016/j.scitotenv.2012.10.061

Wood N and Mason P 1991 The influence of static stability on the effective roughness lengths for momentum and heat transfer Q. J. R. Meteorol. Soc. 117 1025-1056 doi: 10.1002/qj.49711750108

Wyngaard JC and Clifford SF 1978 Estimating momentum, heat and moisture fluxes from structure parameters Journal of the Atmospheric Sciences 35 1204-1211

Wyngaard JC, Izumi Y and Collins JSA 1971 Behavior of the refractive-index-structure parameter near the ground J. Opt. Soc. Am. 61 1646-1650

Yuan R, Luo T, Sun J, Liu H, Fu Y and Wang Z 2016 A new method for estimating aerosol mass flux in the urban surface layer using LAS technology Atmos. Meas. Tech. 9 1925-1937 doi: 10.5194/amt-9-1925-2016

Yuan R, Luo T, Sun J, Zeng Z, Ge C and Fu Y 2015 A new method for measuring the imaginary part of the atmospheric refractive index structure parameter in the urban surface layer Atmos. Chem. Phys. 15 2521-2531 doi: 10.5194/acp-15-2521-2015

Zhang $\mathrm{H}$ and Zhang $\mathrm{H} 2015$ Comparison of turbulent sensible heat flux determined by large-aperture scintillometer and eddy covariance over urban and suburban areas Bound.-Layer Meteor. 154 119-136 doi: 10.1007/s10546-014-9965-8

Zhang H, Zhang H, Cai X, Song Y and Sun J 2016 Contribution of low-frequency motions to sensible heat fluxes over urban and suburban areas Bound.-Layer Meteor. 161 183-201 doi: 10.1007/s10546-016-0163-8

Zieliński M, Fortuniak K, Pawlak W and Siedlecki M 2013 Turbulent sensible heat flux in Łódź, central Poland, obtained from scintillometer and eddy covariance measurements Meteorol. Z. 22 603-613

Zilitinkevich SS, Mammarella I, Baklanov AA and Joffre SM 2008 The effect of stratification on the aerodynamic roughness length and displacement height Bound.-Layer Meteor. 129 179-190 doi: 10.1007/s10546-008-9307-9 